\title{
Mueller matrix ellipsometry studies of nanostructured materials
}

\author{
Roger Magnusson
}

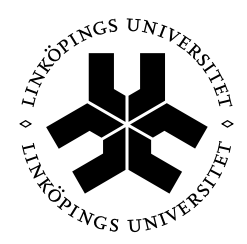

\section{Linköpings universitet}

INSTITUTE OF TECHNOLOGY

\author{
Department of Physics, Chemistry and Biology (IFM) \\ Linköping University, SE-581 83 Linköping, Sweden
}


ISBN 978-91-7519-200-0

ISSN 0345-7524

Printed by LiU-Tryck, Linköping 2014 


\section{Abstract}

Materials can be tailored on the nano-scale to show properties that cannot be found in bulk materials. Often these properties reveal themselves when electromagnetic radiation, e.g. light, interacts with the material. Numerous examples of such types of materials are found in nature. There are for example many insects and birds with exoskeletons or feathers that reflect light in special ways. Of special interest in this work is the scarab beetle Cetonia aurata which has served as inspiration to develop advanced nanostructures due to its ability to turn unpolarized light into almost completely circularly polarized light. The objectives of this thesis are to design and characterize bioinspired nanostructures and to develop optical methodology for their analysis.

Mueller-matrix ellipsometry has been used to extract optical and structural properties of nanostructured materials. Mueller-matrix ellipsometry is an excellent tool for studying the interaction between nanostructures and light. It is a non-destructive method and provides a complete description of the polarizing properties of a sample and allows for determination of structural parameters.

Three types of nanostructures have been studied. The first is an array of carbon nanofibers grown on a conducting substrate. Detailed information on physical symmetries and band structure of the material were determined. Furthermore, changes in its optical properties when the individual nanofibers were electromechanically bent to alter the periodicity of the photonic crystal were studied. The second type of nanostructure studied is bioinspired films with nanospirals of $\operatorname{In}_{x} \mathrm{Al}_{1-x} \mathrm{~N}$ which reflect light with a high degree of circular polarization in a narrow spectral band. These nanostructures were grown under controlled conditions to form columnar structures with an internally graded refractive index responsible for the ability to reflect circularly polarized light. Finally, angle-dependent Mueller matrices were recorded of natural nanostructures in $C$. aurata with the objective to refine the methodology for structural analysis. A Cloude sum decomposition was applied and a more stable regression-based decomposition was developed for deepened analysis of these depolarizing Mueller matrices. It was found that reflection at near-normal incidence from C. aurata can be described as a sum reflection off a mirror and a left-handed circular polarizer. At oblique incidence the description becomes more complex and involves additional optical components. 


\section{Populärvetenskaplig sammanfattning}

Ljus kan beskrivas med inbördes beroende elektriska och magnetiska oscillerande fält som tillsammans bildar en så kallad elektromagnetisk våg. Det elektriska fältets riktning kan användas för att beskriva ljusets polarisation. I opolariserat ljus är riktningarna på svängningarna i det elektriska fältet slumpvis fördelade. Om däremot svängningarna sker i någon ordnad form är ljuset polariserat. Polariserat ljus är i allmänhet elliptiskt polariserat. Vanliga specialfall är dock linjärt polariserat och cirkulärt polariserat ljus. I linjärt polariserat ljus sker alla svängningar i ett och samma plan, medan i cirkulärt eller elliptiskt polariserat ljus samverkar svängningarna så att det elektriska fältet i fronten av vågen skruvar sig fram runt sin egen utbredningsriktning. Oavsett polarisationstillstånd kan ljusvågen beskrivas med fyra parameterar som brukar skrivas i en kolumnvektor, en så kallad Stokesvektor. Om man mäter Stokesvektorn för en ljusstråle som reflekteras mot en yta och därmed ändrar sitt polarisationstillstånd, kan denna förändring beskrivas med hjälp av en så kallad Muellermatris. Denna matris innehåller mycket information om den reflektion som orsakade förändringen och kan mätas med den optiska mätmetoden ellipsometri.

Muellermatrisellipsometri har här använts för att bestämma optiska och strukturella egenskaper hos nanostrukturerade material. Denna metod är ett utmärkt verktyg för att studera sambandet mellan en nanostruktur och hur den interagerar med ljus. Det är en oförstörande metod som ger en fullständig beskrivning av de polariserande egenskaperna hos ett prov. När material är strukturerade med dimensioner på nanometerskalan visar de upp egenskaper som annars inte finns i homogena material. Många exempel på sådana material kan man hitta i naturen. Det finns till exempel många insekter och fåglar med exoskelett eller fjädrar som reflekterar ljus på speciella sätt. Särskilt intressanta är skalbaggar, exempelvis av arten Cetonia aurata (Guldbagge), vilka har fungerat som inspiration för att utveckla avancerade nanostrukturer. Syftet är då att efterlikna skalbaggarnas förmåga att omvandla opolariserat ljus, exempelvis solljus, till nästan helt cirkulärt polariserat ljus.

Tre typer av nanostrukturer har studerats. Den första är en fotonisk kristall bestående av en struktur av kolnanofibrer som tillverkats på ett elektriskt ledande 
substrat. Kolnanofibrerna är ordnade i ett rutnät som har en periodicitet i samma storleksordning som ljusets våglängd och detta gör att ljuset har begränsade möjligheter att utbreda sig i materialet. De enskilda nanofibrerna kan dessutom tillföras laddning som gör att de böjs individuellt på grund av elektrostatiska krafter mellan fibrerna. Detta medför att periodiciteten i den fotoniska kristallen ändras och därmed de optiska egenskaperna. Den andra typen av nanostruktur som studerats utgörs av tunna skikt som inspirerats av ovan nämnda biologiska material. Syntetiska skikt med nanospiraler av $\operatorname{In}_{x} \mathrm{Al}_{1-x} \mathrm{~N}$ reflekterar ljus som generellt är elliptiskt polariserat med en hög grad av cirkulär polarisation inom ett smalt spektralband. När dessa nanostrukturer tillverkas under kontrollerade förhållanden bildar de tättstående pelare, några tiotals nanometer breda och i vårt fall cirka $1 \mu \mathrm{m}$ höga, med ett brytningsindex som varierar inom varje pelare. Detta resulterar i den önskade förmågan att reflektera ljus så att det blir cirkulärt polariserat. Slutligen har vinkel- och våglängdsberoende Muellermatriser uppmätts för naturliga nanostrukturer i $C$. aurata i syfte att förfina metoder för strukturanalys. En så kallad Cloude-dekomposition användes därvid för uppdelning av matriserna och en mer stabil regressionsbaserad dekomposition utvecklades för fördjupad analys. I båda metoderna delas en experimentellt bestämd Muellermatris upp i en summa av upp till fyra andra Muellermatriser som representerar enkla optiska komponenter. Vi fann att reflektion från $C$. aurata vid nästan vinkelrätt infall av ljus kan beskrivas som en summa av reflektioner från en spegel och en vänsterhänt cirkulärpolarisator. Vid snett infall av ljus blir beskrivningen mer komplex och ytterligare optiska komponenter behövs för att beskriva reflektionsegenskaperna. 


\section{Preface}

This thesis was written as a part of my doctoral studies at the Laboratory of Applied Optics at Linköping University and the Department of Physics, Chemistry and Biology. The different topics of my research are spread from scarab beetles via nanostructured artificial materials to matrix decomposition, with a common denominator in ellipsometry.

Many people deserve my thanks for making this possible. Not all will be mentioned here but at least some and first on the list is my supervisor, Hans Arwin. I cannot thank him enough for always finding time to help and for guiding me through it all. His vast knowledge is an inspiration and to have been his student has been a true pleasure. Also my co-supervisor, Kenneth Järrendahl has been very generous with his knowledge and a great support. The rest of my coworkers in the group, Torun Berlind, Christina Åkerlind, Arturo Mendoza Galván, Sergiy and Iryna Valyukh, Lía Fernández del Río, Jan Landin and Johan Gustafson (to mention some) have all contributed to the truly great working environment that is Applied Optics - Thanks!

I also want to thank my collaborators, especially Robert Rehammar at Chalmers in Göteborg and Jens Birch, Per Sandström and Ching-Lien Hsiao from the Thin Film Physics group here in Linköping. A very warm thank you also to Razvigor Ossikovski, Enrique Garcia-Caurel and Clément Fallet at École Polytechnique, Paliseau, France.

A most sincere thank you also to Marcus Ekholm who has been a great friend and inspiration ever since we studied in the physics program together here in Linköping.

To my wife Anna-Karin, our son Viktor and our daughter Emma: Thank you! without you it would be pointless.

This work is supported by a grant from the Swedish Research Council and from the Centre in Nano science and technology (CeNano) at Linköping University. Knut and Alice Wallenberg foundation is acknowledged for support to instrumentation.

Roger Magnusson

Linköping, November 2014 


\section{Contents}

1 Introduction $\quad 1$

2 A brief outline of electromagnetic theory 3

3 Polarization $\mathbf{5}$

3.1 Stokes vectors . . . . . . . . . . . . . . . 6

3.1.1 Examples of Stokes vectors for various polarization states . 8

3.2 Mueller matrices . . . . . . . . . . . . . . . . . 9

3.2.1 Rotation of optical components . . . . . . . . . . . 10

3.2.2 Examples of Mueller matrices . . . . . . . . . . . . 11

3.3 Depolarization . . . . . . . . . . . . . . . . . 13

4 Decomposition $\quad 17$

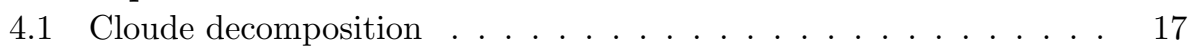

4.2 Regression decomposition . . . . . . . . . . . . . . . 20

5 Photonic crystals $\quad \mathbf{2 5}$

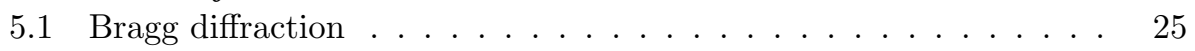

5.2 Circular Bragg phenomenon . . . . . . . . . . . . 25

6 Ellipsometry 29

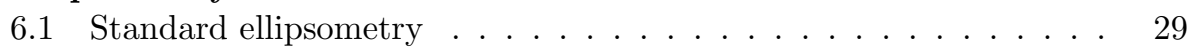

6.2 Mueller-matrix ellipsometry . . . . . . . . . . . . . . 30

6.3 Ellipsometer setup . . . . . . . . . . . . . . . . . . . 32

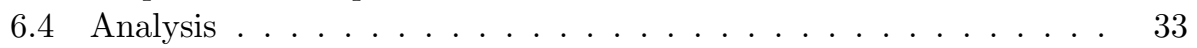

7 Sample preparation $\quad 35$

7.1 Carbon nano fibers . . . . . . . . . . . . . . . . . . . 35

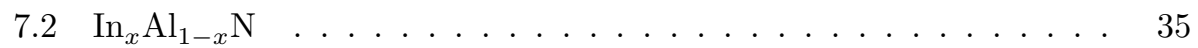

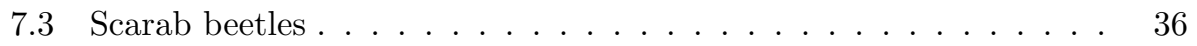

$\begin{array}{lll}8 & \text { Outlook } & 37\end{array}$ 
$\begin{array}{ll}\text { Bibliography } & 39\end{array}$

List of publications $\quad 45$

Article I

Chirality-induced polarization effects in the cuticle of scarab beetles: 100 years after Michelson

Article II

Chiral nanostructures producing near circular polarization

Article III

Optical Mueller Matrix Modeling of Chiral $\mathbf{A l}_{x} \mathbf{I n}_{1-x} \mathbf{N}$ Nanospirals

Article IV

Optical properties of carbon nanofiber photonic crystals

Article V

Electromechanically Tunable Carbon Nanofiber Photonic Crystal101

Article VI

Sum decomposition of Mueller-matrix images and spectra of beetle cuticles

Article VII

Sum regression decomposition of spectral and angle-resolved Muellermatrices from biological reflectors 


\section{Chapter 1}

\section{Introduction}

With nanotechnology, materials can be tailored down to their smallest building blocks - the atoms - which may result in new and exciting properties. When the dimensions of structures are on the nanoscale, interaction with light is governed by other principles compared to when light interacts with "normal" materials and the results can be quite stunning. If we look in nature we find that it is not uncommon that many brilliant colors in the world of insects are due to nanostructures and not pigments and many times in combination with intriguing optical effects. This is the case for example with the iridescent blue wings of the butterfly Morpho rhetenor or the green, almost jewelry-like exoskeletons of some beetles discussed in this thesis.

In fact there are numerous natural nanostructures which exhibit visual and polarizing effects. In addition these structures are often multifunctional and show properties such as super-hydrophobicity, hardness, ultraviolet protection, infrared thermal control to name a few. In this thesis natural as well as synthetic photonic structures with multilayered, chiral and photonic-crystal based nanostructures have been studied with Mueller-matrix ellipsometry to investigate the physical origin of structural colors and complex polarization properties.

The overall objective is to design and fabricate nanostructures with desired optical properties and to characterize them. With Mueller-matrix ellipsometry it is possible to extract complete information about the polarizing properties of a sample and with state-of-the-art instruments at my disposal I have investigated photonic crystals, natural nanostructures in beetles and chiral $\operatorname{In}_{x} \mathrm{Al}_{1-x} \mathrm{~N}$ nanostructured films. In order to develop the methodology for optical analysis of such nanostructures a regression-based sum decomposition has been developed and tested for some of the beetles studied. When fully developed, this might serve as a classification for natural reflectors.

There are many examples where mimicking natural structures have very useful applications, like antireflective coatings mimicking moth eyes [1], selective gas sensors based on structures as found in the wings of the butterfly Morpho sulkowskyi [2] 
or tunable structural colors [3]. Structural colors do not fade as pigment colors tend to do, and combining such properties with exceptional mechanical properties could prove very valuable. I am sure that many more natural structures can provide inspiration for applications that require unique optical performance and hope that the results in this thesis may provide a platform for development of applications like multifunctional decorative coatings, polarization devices and more. 


\section{Chapter 2}

\section{A brief outline of electromagnetic theory}

Light is described by a transverse electromagnetic plane wave which is a solution to Maxwell's equations. Maxwell's equations in differential form is given by [4]

$$
\begin{aligned}
\nabla \times \mathbf{E} & =-\frac{\partial \mathbf{B}}{\partial t} \\
\nabla \times \mathbf{H} & =\mathbf{J}+\frac{\partial \mathbf{D}}{\partial t} \\
\nabla \cdot \mathbf{D} & =\rho \\
\nabla \cdot \mathbf{B} & =0
\end{aligned}
$$

where $\mathbf{E}$ and $\mathbf{H}$ are the electric field and the magnetic field strength, respectively. $\mathbf{D}$ is the electric displacement field and $\mathbf{B}$ is the magnetic flux density. $\rho$ and $\mathbf{J}$ are the electric charge density and current density, respectively. Material properties are introduced by specifying the so called constitutive relations [5]

$$
\begin{aligned}
& \mathbf{D}=\epsilon_{0} \epsilon \mathbf{E} \\
& \mathbf{B}=\mu_{0} \mu \mathbf{H}
\end{aligned}
$$

where $\epsilon_{0}$ and $\mu_{0}$ are the free space permittivity and permeability, respectively, $\epsilon$ the dielectric tensor and $\mu$ is the magnetic permeability tensor. At optical frequencies $\mu$ does not differ much from its vacuum value [5] and can be set to unity.

We can now completely describe the linear optical properties of a material with the dielectric tensor

$$
\epsilon=\left[\begin{array}{ccc}
\epsilon_{x x} & \epsilon_{x y} & \epsilon_{x z} \\
\epsilon_{y x} & \epsilon_{y y} & \epsilon_{y z} \\
\epsilon_{z x} & \epsilon_{z y} & \epsilon_{z z}
\end{array}\right]
$$

where each component $\epsilon_{i j}$ is a complex-valued quantity and relates how the medium responds to an external electric field. Monoclinic, triclininc and gyrotropic mate- 
rials [6] may have off-axis contributions in the dielectric tensor but they will not be discussed in this work. What is left is a diagonal tensor if the optical axes are parallel to the $x$-, $y$ - and $z$-axes of the coordinate system. Equation 2.7 can then be rewritten as

$$
\epsilon=\left[\begin{array}{ccc}
\epsilon_{x} & 0 & 0 \\
0 & \epsilon_{y} & 0 \\
0 & 0 & \epsilon_{z}
\end{array}\right]
$$

where a shorter notation has been used in the subscripts. If $\epsilon_{x}=\epsilon_{y}=\epsilon_{z}$ the medium is said to be isotropic and the optical response does not depend on the orientation of the crystal with respect to the applied electric field. For an anisotropic medium there are two different options. If $\epsilon_{x} \neq \epsilon_{y} \neq \epsilon_{z}$ the optical response is different in three directions and the material is said to be biaxially anisotropic, or biaxial. If two of them are equal it is uniaxially anisotropic, or uniaxial.

The optical response is in general dependent on the frequency, $\omega$, of the applied electric field and for an isotropic medium it is possible to describe the optical response with a scalar dielectric function as

$$
\epsilon(\omega)=\epsilon_{1}(\omega)+i \epsilon_{2}(\omega)
$$

The complex refractive index is another way to describe the optical response of a material when light interacts with it. It is denoted

$$
N=n+i k
$$

The real part, $n$, is the ratio of the speed of light, $c_{0}$, in free space and the speed of light inside the medium, $v$, i.e.

$$
n=\frac{c_{0}}{v}
$$

The imaginary part, $k$, is the extinction coefficient describing how the electric field attenuates inside the medium, e.g. along the z-axis, as

$$
E(z)=E_{0} e^{-\frac{2 \pi k}{\lambda} z}
$$

where $E_{0}$ is the electric field at $\mathrm{z}=0$. The refractive index is related to the dielectric function as

$$
N=\sqrt{\epsilon}
$$

For an anisotropic medium the dielectric tensor can thus be written as

$$
\epsilon=\left[\begin{array}{ccc}
N_{x}^{2} & 0 & 0 \\
0 & N_{y}^{2} & 0 \\
0 & 0 & N_{z}^{2}
\end{array}\right]
$$

where $N_{x}, N_{y}$ and $N_{z}$ are the refractive indices in different directions of a biaxial material. 


\section{Chapter 3}

\section{Polarization}

Consider light propagating in the $z$-direction of a Cartesian coordinate system. The electric field $\mathbf{E}$ varies in time $t$ as

$$
\mathbf{E}(z, t)=\mathbf{E}_{x}(z, t)+\mathbf{E}_{y}(z, t)=E_{x}(t) \cos \left(q z-\omega t+\delta_{x}(t)\right) \hat{x}+E_{y}(t) \cos \left(q z-\omega t+\delta_{y}(t)\right) \hat{y}
$$

where $\mathbf{E}_{x}$ and $\mathbf{E}_{y}$ are components of the total field $\mathbf{E} . E_{x}, E_{y}$ and $\delta_{x}, \delta_{y}$ are amplitudes and phases, respectively, of the components. We will here consider only a real-valued propagation constant $q$, i.e. light propagating in non-absorbing media (air). The plane-of-vibration of the electric field is what defines the polarization state of the light. When the fields $E_{x}$ and $E_{y}$ in equation 3.1 have the same amplitude and the same phase, the resulting field $\mathbf{E}$ is linearly polarized at a $45^{\circ}$ angle between the $x$ - and $y$-axis as depicted in figure 3.1. A phase shift of $180^{\circ}$
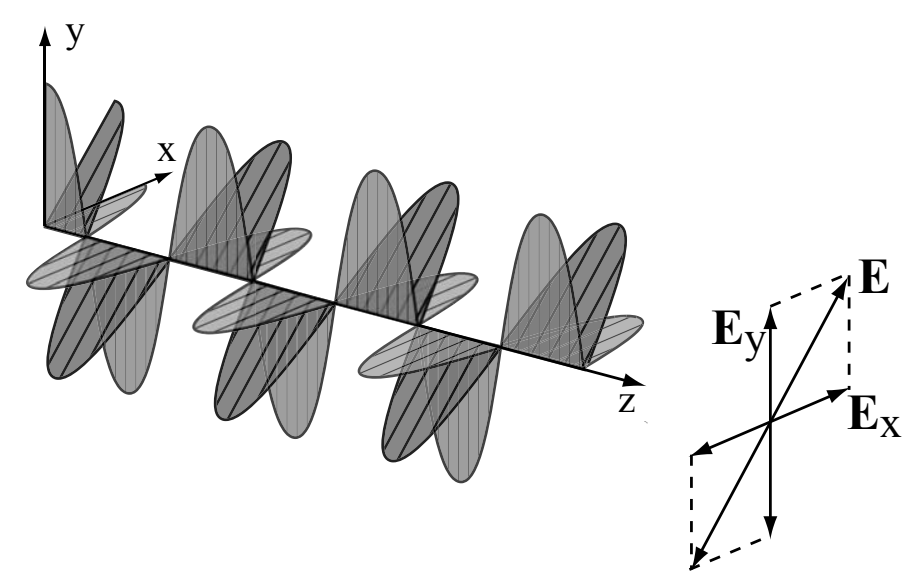

Figure 3.1. A schematic description of linearly polarized light. 
(i.e. half a wavelength) of either $\mathbf{E}_{x}$ or $\mathbf{E}_{y}$ will also result in linearly polarized light, but then its direction of polarization will be at $-45^{\circ}$ with respect to the $x$-direction. If a phase shift of a quarter of a wavelength, i.e. $\pm 90^{\circ}$, is introduced the resulting field $\mathbf{E}$ will have constant amplitude and rotate around the $z$-axis as schematically shown in figure 3.2. In figure 3.2 the phase shift is $+90^{\circ}$ which results in left-handed circular polarization. A phase shift of $-90^{\circ}$ yields righthanded circular polarization. Any phase shift other than $0^{\circ}, \pm 90^{\circ}$ or $\pm 180^{\circ}$ yields elliptical polarization.

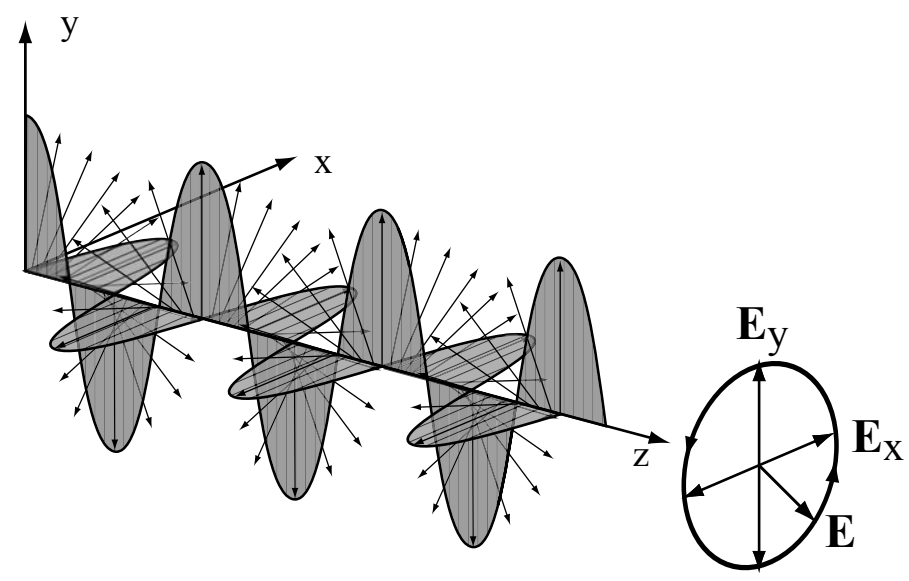

Figure 3.2. A schematic description of left-handed circularly polarized light.

\subsection{Stokes vectors}

The polarization properties of an electromagnetic plane wave can be described by four measurable irradiances originally presented by Sir George Gabriel Stokes in 1852 [7]. The Stokes parameters are defined as the time-averaged quantities ${ }^{1}$

$$
\begin{aligned}
I & =\left\langle E_{x}^{2}\right\rangle+\left\langle E_{y}^{2}\right\rangle \\
Q & =\left\langle E_{x}^{2}\right\rangle-\left\langle E_{y}^{2}\right\rangle \\
U & =2\left\langle E_{x} E_{y} \cos \left(\delta_{y}-\delta_{x}\right)\right\rangle \\
V & =2\left\langle E_{x} E_{y} \sin \left(\delta_{y}-\delta_{x}\right)\right\rangle
\end{aligned}
$$

where $E_{x}$ and $E_{y}$ are the orthogonal components of the electric field described as in equation 3.1. With the square of the amplitude of the electric field being

\footnotetext{
${ }^{1} \mathrm{~A}$ constant prefactor $\epsilon_{0} c_{0} / 2$ has been dropped for all four Stokes parameters as is common practice [8].
} 
proportional to irradiance, $I$, equations 3.1 can also be written as

$$
\begin{aligned}
& I=I_{x}+I_{y} \\
& Q=I_{x}-I_{y} \\
& U=I_{+45^{\circ}}-I_{-45^{\circ}} \\
& V=I_{r}-I_{l}
\end{aligned}
$$

where $I_{x, y,+45^{\circ},-45^{\circ}, r, l}$ denote irradiance for light polarized according to figure 3.3. The Stokes parameters can easily be calculated from measured irradiances [9]. The
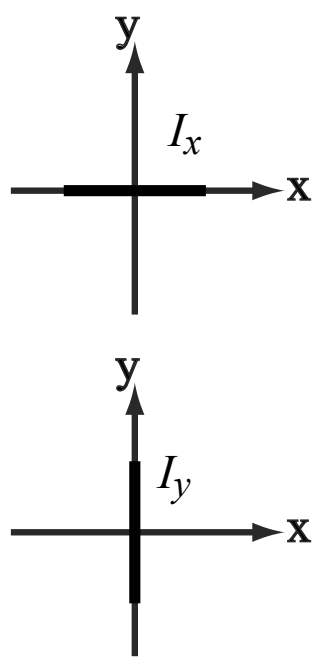
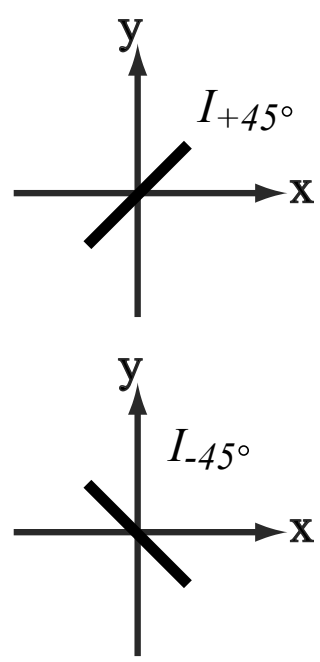
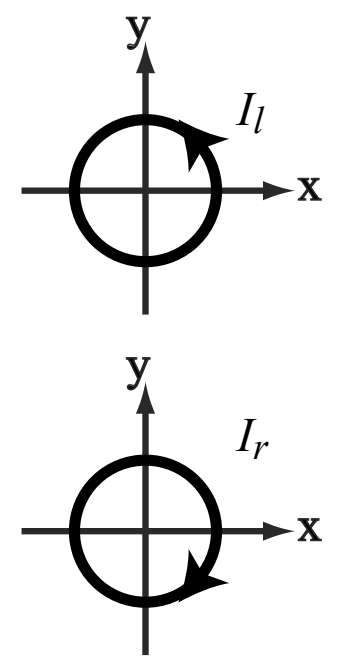

Figure 3.3. The polarization states, when looking into the light source, of which the irradiances need to be measured to calculate the Stokes parameters.

first parameter, $I$, is the total irradiance and the remaining three describe the polarization state of the light. $Q$ represents the amount of linear polarization in the $x$-direction when it is positive and in the $y$-direction when it is negative, $U$ represents the amount of linear polarization in $+45^{\circ}$ and $-45^{\circ}$ when it is positive and negative, respectively. The Stokes parameter $V$ represents the amount of right- and left-handed circularly polarized light. The four Stokes parameters can be arranged in a column matrix and written as

$$
\mathbf{S}=\left[\begin{array}{c}
I \\
Q \\
U \\
V
\end{array}\right]
$$

and even if it is not mathematically a vector it is normally called a Stokes vector. 


\subsubsection{Examples of Stokes vectors for various polarization states}

Unpolarized light has equal amounts of $x$ - and $y$-polarized light as well as $+45^{\circ}$ and $-45^{\circ}$ and right- and left-handed circularly polarized light. According to equation 3.1 the Stokes vector for unpolarized light will therefore be

$$
\mathbf{S}=I_{0}\left[\begin{array}{l}
1 \\
0 \\
0 \\
0
\end{array}\right]
$$

where $I_{0}$ is the total irradiance. Normally it is convenient to normalize the Stokes vector to the total irradiance by dividing each parameter with $I_{0}$ and this convention will be used throughout this thesis. Horizontally polarized light has an electric field that oscillates in the $x$-direction and no vertical component and thus $I_{x}+I_{y}=I_{x}, I_{x}-I_{y}=I_{x}$ and $I_{+45^{\circ}}=I_{-45^{\circ}}=I_{r}=I_{l}=0$. The Stokes vector of such light is

$$
\mathbf{S}=I_{0}\left[\begin{array}{l}
1 \\
1 \\
0 \\
0
\end{array}\right]
$$

Perpendicular to horizontally polarized light is vertically polarized light with an electric field oscillating in the $y$-direction and the Stokes vector for such light is

$$
\mathbf{S}=I_{0}\left[\begin{array}{c}
1 \\
-1 \\
0 \\
0
\end{array}\right]
$$

Light polarized at $+45^{\circ}$ or $-45^{\circ}$ to the $x$-direction has equal irradiances in the $x$ and $y$-directions so $I_{x}=I_{y}$ which yields Stokes vectors according to

$$
\mathbf{S}=I_{0}\left[\begin{array}{l}
1 \\
0 \\
1 \\
0
\end{array}\right]
$$

and

$$
\mathbf{S}=I_{0}\left[\begin{array}{c}
1 \\
0 \\
-1 \\
0
\end{array}\right]
$$

respectively.

Right-handed circularly polarized light has an E-vector that is rotating clockwise when you are looking into the light source. The Stokes vector of such a light 
beam is

$$
\mathbf{S}=I_{0}\left[\begin{array}{l}
1 \\
0 \\
0 \\
1
\end{array}\right]
$$

and the Stokes vector for left-handed circularly polarized light where the E-vector is rotating counterclockwise is

$$
\mathbf{S}=I_{0}\left[\begin{array}{c}
1 \\
0 \\
0 \\
-1
\end{array}\right]
$$

The degree of polarization can vary from zero (completely unpolarized) to one (completely polarized). If only part of the irradiance of the light is polarized, one can define the degree of polarization, $P$, as $I_{p o l} / I_{t o t}$, where $I_{p o l}$ is the polarized part and $I_{\text {tot }}$ is the total irradiance. $P$ is is calculated from the Stokes vector of the light by [10]

$$
P=\frac{\sqrt{Q^{2}+U^{2}+V^{2}}}{I}
$$

\subsection{Mueller matrices}

When light interacts with matter, either through transmission or reflection or a combination of both, the polarization state of the light beam changes which is schematically shown in figure 3.4. Using Stokes formalism P. Soleillet [11] and later F. Perrin [12] showed how a transformation from an incident polarization state, $\left[I_{i}, Q_{i}, U_{i}, V_{i}\right]^{T}$, to an emerging state, $\left[I_{o}, Q_{o}, U_{o}, V_{o}\right]^{T}$, can be expressed as a linear combination of the four Stokes parameters of the incident light as

$$
\begin{aligned}
I_{o} & =M_{11} I_{i}+M_{12} Q_{i}+M_{13} U_{i}+M_{14} V_{i} \\
Q_{o} & =M_{21} I_{i}+M_{22} Q_{i}+M_{23} U_{i}+M_{24} V_{i} \\
U_{o} & =M_{31} I_{i}+M_{32} Q_{i}+M_{33} U_{i}+M_{34} V_{i} \\
V_{o} & =M_{41} I_{i}+M_{42} Q_{i}+M_{43} U_{i}+M_{44} V_{i}
\end{aligned}
$$

Later it was put into matrix form by Hans Mueller [13] who has given name to the formalism. He did not publish his work himself but it has been made known through the work of his student N. G. Parke III [14]. In matrix form we then have

$$
\left[\begin{array}{c}
I_{o} \\
Q_{o} \\
U_{o} \\
V_{o}
\end{array}\right]=\left[\begin{array}{llll}
M_{11} & M_{12} & M_{13} & M_{14} \\
M_{21} & M_{22} & M_{23} & M_{24} \\
M_{31} & M_{32} & M_{33} & M_{34} \\
M_{41} & M_{42} & M_{43} & M_{44}
\end{array}\right]\left[\begin{array}{c}
I_{i} \\
Q_{i} \\
U_{i} \\
V_{i}
\end{array}\right]
$$

or

$$
\mathbf{S}_{\mathbf{o}}=\mathbf{M S}_{\mathbf{i}}
$$



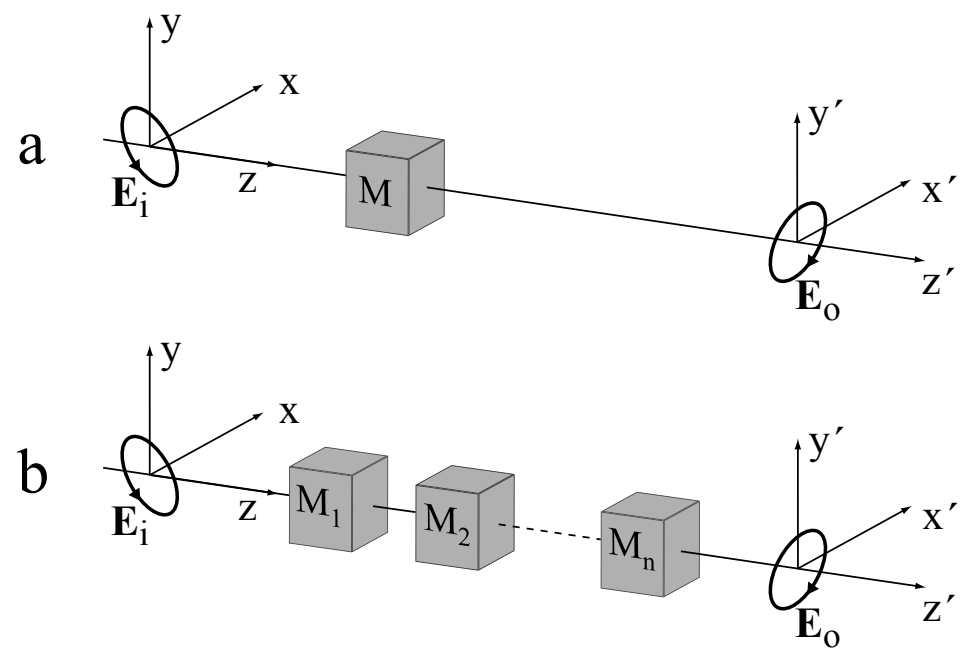

Figure 3.4. Interaction of light with a) one optical system $\mathbf{M}$ and b) $n$ optical systems $\mathbf{M}_{1}, \mathbf{M}_{2}, \ldots, \mathbf{M}_{n} . \mathbf{E}_{i}$ and $\mathbf{E}_{o}$ indicate the polarization ellipse of polarized part of the incident and emerging light, respectively.

where the $4 \times 4$ matrix $\mathbf{M}$ is called the Mueller matrix. In the previous section we defined the first of the four Stokes parameters as the total irradiance of the light. Since the irradiance seldom is of importance in ellipsometry, the Stokes vector is usually normalized to the first parameter. In accordance with this the Mueller matrix is normalized to $M_{11}$ and we define $m_{i j}=M_{i j} / M_{11}(i, j=1,2,3,4)$. Then, equation 3.20 becomes

$$
\left[\begin{array}{c}
I_{o} \\
Q_{o} \\
U_{o} \\
V_{o}
\end{array}\right]=\left[\begin{array}{cccc}
1 & m_{12} & m_{13} & m_{14} \\
m_{21} & m_{22} & m_{23} & m_{24} \\
m_{31} & m_{32} & m_{33} & m_{34} \\
m_{41} & m_{42} & m_{43} & m_{44}
\end{array}\right]\left[\begin{array}{c}
1 \\
Q_{i} \\
U_{i} \\
V_{i}
\end{array}\right]
$$

When light interacts with several optical systems in cascade as in figure $3.4 \mathrm{~b}$, the Stokes vector of the emerging light is calculated by

$$
S_{\mathrm{o}}=\mathrm{M}_{\mathbf{n}} \ldots \mathrm{M}_{2} \mathrm{M}_{1} \mathrm{~S}_{\mathrm{i}}
$$

where $\mathbf{M}_{1,2, \ldots, n}$ are the Mueller matrices of the individual optical systems. The combined effect of all the $\mathbf{M}_{i}$ can be expressed as one Mueller matrix, $\mathbf{M}=$ $\mathbf{M}_{\mathbf{n}} \ldots \mathbf{M}_{\mathbf{2}} \mathbf{M}_{\mathbf{1}}$, by matrix multiplication.

\subsubsection{Rotation of optical components}

When an optical device is rotated around the axis of light propagation (the $z$ axis of a Cartesian system) the coordinate system of the light and that of the 
component are no longer the same and a transformation of the description of the device properties from the light coordinate system to the component system, and back is required to calculate the optical response of the component. The Mueller matrix $\mathbf{M}^{r}$ of a component that has been rotated an angle $\alpha$ with respect to the $x$-axis will be $[15]$

$$
\mathbf{M}^{\mathbf{r}}=\mathbf{R}(-\alpha) \mathbf{M R}(\alpha)
$$

where $\mathbf{M}$ is the Mueller matrix of the unrotated device and $\mathbf{R}(\alpha)$ is given by

$$
\mathbf{R}(\alpha)=\left[\begin{array}{cccc}
1 & 0 & 0 & 0 \\
0 & \cos 2 \alpha & \sin 2 \alpha & 0 \\
0 & -\sin 2 \alpha & \cos 2 \alpha & 0 \\
0 & 0 & 0 & 1
\end{array}\right]
$$

\subsubsection{Examples of Mueller matrices}

Here follows a selection of Mueller matrices for some optical devices of relevance for this thesis. All devices are assumed to be illuminated at normal incidence and to transmit or reflect light parallel to the $z$-axis of a Cartesian coordinate system.

\section{Linear diattenuator}

A linear diattenuator (also called a polarizer) decreases the amplitude of the electric field in two orthogonal directions of an electromagnetic wave without affecting their phase difference. The Mueller matrix of a general diattenuator is given by

$$
\mathbf{M}_{P}=\frac{1}{2}\left[\begin{array}{cccc}
p_{x}^{2}+p_{y}^{2} & p_{x}^{2}-p_{y}^{2} & 0 & 0 \\
p_{x}^{2}-p_{y}^{2} & p_{x}^{2}+p_{y}^{2} & 0 & 0 \\
0 & 0 & 2 p_{x} p_{y} & 0 \\
0 & 0 & 0 & 2 p_{x} p_{y}
\end{array}\right]
$$

where $p_{x}$ and $p_{y}$ are the real-valued amplitude transmission coefficients along orthogonal transmission axis, respectively, and can vary in value between zero and unity. If one of the transmission coefficients are zero we have an ideal linear polarizer. When e.g. $p_{y}=0$, equation 3.26 reduces to

$$
\mathbf{M}_{P}^{\text {horizontal }}=\frac{1}{2}\left[\begin{array}{llll}
1 & 1 & 0 & 0 \\
1 & 1 & 0 & 0 \\
0 & 0 & 0 & 0 \\
0 & 0 & 0 & 0
\end{array}\right]
$$

which is an ideal linear horizontal polarizer, transmitting only light polarized in the $x$-direction. The reverse, $p_{x}=0$, gives an ideal linear vertical polarizer with a Mueller matrix as

$$
\mathbf{M}_{P}^{\text {vertical }}=\frac{1}{2}\left[\begin{array}{cccc}
1 & -1 & 0 & 0 \\
-1 & 1 & 0 & 0 \\
0 & 0 & 0 & 0 \\
0 & 0 & 0 & 0
\end{array}\right]
$$


In paper VII en elliptical polarizer is used with Mueller matrix

$$
\mathbf{M}_{P}^{\text {elliptic }}=\frac{1}{2}\left[\begin{array}{cccc}
1 & \cos \varepsilon & 0 & \sin \varepsilon \\
\cos \varepsilon & \cos ^{2} \varepsilon & 0 & \cos \varepsilon \sin \varepsilon \\
0 & 0 & 0 & 0 \\
\sin \varepsilon & \cos \varepsilon \sin \varepsilon & 0 & \sin ^{2} \varepsilon
\end{array}\right]
$$

When the angle $\varepsilon$ goes through values of $0^{\circ}, 90^{\circ}, 180^{\circ}$ and $270^{\circ}$ the outgoing light will be horizontally polarized, right-handed circularly polarized, vertically polarized and left-handed circularly polarized, respectively, if the incident light is unpolarized.

\section{Retarder}

A retarder induces a phase shift in the electric field between two orthogonal directions. This effect is achieved when one direction, called the slow axis, has a longer optical path length than the orthogonal, fast axis, inside the material that constitutes the retarder. A general linear retarder with its fast axis parallel to the $\mathrm{x}$-axis of a Cartesian coordinate system has a Mueller matrix according to

$$
\mathbf{M}_{R}=\left[\begin{array}{cccc}
1 & 0 & 0 & 0 \\
0 & 1 & 0 & 0 \\
0 & 0 & \cos \delta & \sin \delta \\
0 & 0 & -\sin \delta & \cos \delta
\end{array}\right]
$$

where $\delta$ is the phase delay, i.e. the retardation. A retarder that has been rotated an angle $\alpha$ according to equation 3.24 has a Mueller matrix

$$
M_{R}^{\text {linear }}=\left[\begin{array}{cccc}
1 & 0 & 0 & 0 \\
0 & \cos ^{2} 2 \alpha+\cos \delta \sin ^{2} 2 \alpha & (1-\cos \delta) \cos 2 \alpha \sin 2 \alpha & -\sin \delta \sin 2 \alpha \\
0 & (1-\cos \delta) \cos 2 \alpha \sin 2 \alpha & \cos \delta \cos ^{2} 2 \alpha+\sin ^{2} 2 \alpha & \cos 2 \alpha \sin \delta \\
0 & \sin \delta \sin 2 \alpha & -\cos 2 \alpha \sin \delta & \cos \delta
\end{array}\right]
$$

There are two special types of retarders that are often referred to in polarizing optics. These are called a quarter-wave retarder and a half-wave retarder and have retardation $90^{\circ}$ and $180^{\circ}$, respectively. A quarter-wave retarder delays the phase of one component of the electric field with respect to the orthogonal component by one quarter of a wavelength, and a half-wave retarder delays the component half a wavelength. For a quarter-wave retarder with its fast axis along the $x$-axis we have

$$
\mathbf{M}_{R}^{\text {horizontal }}=\left[\begin{array}{cccc}
1 & 0 & 0 & 0 \\
0 & 1 & 0 & 0 \\
0 & 0 & 0 & 1 \\
0 & 0 & -1 & 0
\end{array}\right]
$$

and when the fast axis is along the $y$-axis we have

$$
\mathbf{M}_{R}^{\text {vertical }}=\left[\begin{array}{cccc}
1 & 0 & 0 & 0 \\
0 & 1 & 0 & 0 \\
0 & 0 & 0 & -1 \\
0 & 0 & 1 & 0
\end{array}\right]
$$


When $\delta$ is $180^{\circ}$ for a retarder with its fast axis along the $x$-axis, equation 3.31 reduces to

$$
\mathbf{M}_{R}^{h w}=\left[\begin{array}{cccc}
1 & 0 & 0 & 0 \\
0 & 1 & 0 & 0 \\
0 & 0 & -1 & 0 \\
0 & 0 & 0 & -1
\end{array}\right]
$$

\section{Circular polarization}

As shown in figure 3.2 a quarter wavelength phase shift between orthogonal components of the electric field with equal amplitudes results in circular polarization. This can be achieved by having a linear polarizer rotated $+45^{\circ}$ or $-45^{\circ}$ with respect to the fast axis of a subsequent quarter-wave retarder. The combined effect can be represented by a single Mueller matrix for a right-handed circular polarizer [16]

$$
\mathbf{M}_{C}^{\text {right }}=\frac{1}{2}\left[\begin{array}{llll}
1 & 0 & 0 & 1 \\
0 & 0 & 0 & 0 \\
0 & 0 & 0 & 0 \\
1 & 0 & 0 & 1
\end{array}\right]
$$

if the orientation of the fast axis of the retarder is $+45^{\circ}$ with respect to the linear polarization and a left-handed circular polarizer

$$
\mathbf{M}_{C}^{\text {left }}=\frac{1}{2}\left[\begin{array}{cccc}
1 & 0 & 0 & -1 \\
0 & 0 & 0 & 0 \\
0 & 0 & 0 & 0 \\
-1 & 0 & 0 & 1
\end{array}\right]
$$

if the orientation is $-45^{\circ}$.

\section{A reflecting surface}

When looking into a mirror, right becomes left and left becomes right. Also the reflection of the arms of a wrist watch will appear to be moving in a counter clockwise direction. This is equivalent to the effects of the Mueller matrix in equation 3.34

$$
\mathbf{M}_{m}=\left[\begin{array}{cccc}
1 & 0 & 0 & 0 \\
0 & 1 & 0 & 0 \\
0 & 0 & -1 & 0 \\
0 & 0 & 0 & -1
\end{array}\right]
$$

\subsection{Depolarization}

Depolarization is a process where the degree of polarization decreases. The origin of depolarization in a reflection measurement can be backside reflection for transparent samples, angular spread or finite bandwidth of the incident light or when a sample has spatially varying optical response inside the beam spot. For thin film samples thickness non-uniformity is a common source of depolarization. 
Depolarization can also be the result of scattering or rapidly varying diattenuation or retardance [17]. The Mueller matrix of a normalized diagonal depolarizer is

$$
\mathbf{M}_{D}=\left[\begin{array}{llll}
1 & 0 & 0 & 0 \\
0 & a & 0 & 0 \\
0 & 0 & b & 0 \\
0 & 0 & 0 & c
\end{array}\right]
$$

where $a, b$ and $c$ can take on values between 0 when $\mathbf{M}_{D}$ is an ideal depolarizer, and unity. In the latter case $\mathbf{M}_{D}$ is called a neutral density filter and does not affect the polarization state but reduces the irradiance due to a transmittance less than one (not seen in equation 3.38 as $\mathbf{M}_{D}$ is normalized). When $a=b=c \neq 1$ the polarization state of the incident light is preserved but the degree of polarization is reduced. For a diagonal depolarizer with $a \neq b \neq c$ the polarization state as well as the degree of polarization is changed.

As described by equation 3.18 the degree of polarization of a light beam can be calculated from the Stokes parameters. When we classify materials based on their ability to turn unpolarized light into polarized light in papers I and II we have used the following definition. When unpolarized, i.e. $\mathbf{S}_{i}=[1,0,0,0]^{T}$, shines on a sample the outgoing Stokes vector $\mathbf{S}_{o}$ will be identical to the first column of the sample Mueller matrix. These matrix elements are then used to calculate $P$ and give a measure of the polarizing ability of the sample when illuminated by unpolarized light. However, in papers VI and VII depolarizing Mueller matrices are discussed and more general measures of the depolarizing properties of the matrix is needed. Gil and Bernabeu [18] introduced a Depolarization Index $\left(P_{D}\right)$

$$
P_{D}=\sqrt{\frac{\left(\sum_{i, j=1}^{4} m_{i j}^{2}-m_{11}^{2}\right)}{3 m_{11}^{2}}}
$$

which gives an average measure of the depolarizing power of the optical system. A non-depolarizing system has $P_{D}=1$ and a pure depolarizer has $P_{D}=0$.

A slightly different approach was introduced by Chipman [19]. The Average Degree of Polarization (ADoP), is defined as the mean of the polarization of the exiting light when all incident polarization states (with Stokes vector $\mathbf{S}_{i}$ ) are represented. It is calculated by

$$
\operatorname{ADoP}(\mathbf{M})=\frac{1}{4 \pi} \int_{0}^{\pi} \int_{-\pi / 2}^{\pi / 2} \operatorname{DoP}\left(\mathbf{M S}_{i}(\theta, \epsilon)\right) \cos (\epsilon) \mathrm{d} \theta \mathrm{d} \epsilon
$$

where $\theta$ and $\epsilon$ are the azimuth and ellipticity of the polarization ellipse corresponding to $\mathbf{S}_{i}$ and DoP is the operator for calculating $P$ from equation 3.18.

A third option for determining the depolarization power is to use the Jones Matrix Quality $\left(Q_{J M}\right)$. This involves converting a Jones matrix $\mathbf{J}$ to a Mueller matrix $\mathbf{M}^{J}$ by calculating [15]

$$
\mathbf{M}^{J}=\mathbf{A} \mathbf{J} \otimes \mathbf{J}^{*} \mathbf{A}^{-1}
$$


where $\otimes$ is the Kronecker product, * indicates complex conjugate and

$$
\mathbf{A}=\left[\begin{array}{cccc}
1 & 0 & 0 & 1 \\
1 & 0 & 0 & -1 \\
0 & 1 & 1 & 0 \\
0 & i & -i & 0
\end{array}\right]
$$

The $Q_{J M}$ is then calculated by comparing the experimentally determined Mueller matrix $\mathbf{M}$ to the calculated Jones matrix $\mathbf{M}^{J}$ where the elements in $\mathbf{M}^{J}$ have been fitted by non-linear regression to minimize

$$
Q_{J M}=1000\left\|\mathbf{M}-\mathbf{M}^{J}\right\|_{F}=1000 \sqrt{\sum_{i=1}^{4} \sum_{j=1}^{4}\left|M_{i j}-M_{i j}^{J}\right|^{2}}
$$

A low value in $Q_{J M}$ is only possible when the conversion between a Jones matrix and a Mueller matrix is successful. If there is a one-to-one conversion between a Mueller matrix and a Jones matrix it means that no depolarization is present. Large values in $Q_{J M}$ means that it is not possible to find a good match between the matrices $\mathbf{M}^{J}$ and $\mathbf{M}$, which in turn is due to depolarization. An example is shown in section 4.1 . 


\section{Chapter 4}

\section{Decomposition}

\subsection{Cloude decomposition}

Any physically realizable depolarizing Mueller matrix $\mathbf{M}$ can be decomposed into a set of up to four non-depolarizing matrices $\mathbf{M}_{i}[20]$ as

$$
\mathbf{M}=\sum_{i=1}^{4} \lambda_{i} \mathbf{M}_{i}
$$

where $\lambda_{i}$ are non-negative scalars. Notice that it is the sum of matrices $\mathbf{M}_{i}$ that equals the original Mueller matrix and not a product as in equation 3.23. This decomposition is then analogous to having several optical systems in parallel, not in sequence as in figure $3.4 \mathrm{~b}$. To do the decomposition we will start with the covariance matrix $\mathbf{C}$, which is obtained by the following operation [20, 21]:

$$
\mathbf{C}=\sum_{i, j} m_{i j}\left(\sigma_{i} \otimes \sigma_{j}^{*}\right)
$$

Here $m_{i j}$ with $i, j=1,2,3,4$ are the elements of the Mueller matrix to be decomposed and $\sigma_{i}$ are the Pauli spin matrices

$$
\sigma_{1}=\left[\begin{array}{ll}
1 & 0 \\
0 & 1
\end{array}\right] \quad \sigma_{2}=\left[\begin{array}{cc}
1 & 0 \\
0 & -1
\end{array}\right] \quad \sigma_{3}=\left[\begin{array}{ll}
0 & 1 \\
1 & 0
\end{array}\right] \quad \sigma_{2}=\left[\begin{array}{cc}
0 & -i \\
i & 0
\end{array}\right]
$$

The covariance matrix contains the same information as the Mueller matrix, only the elements are arranged in a way that it makes a $4 \times 4$ positive semidefinite Hermitian matrix. We can now, analogous to equation 4.1 write

$$
\mathbf{C}=\sum_{i=1}^{4} \lambda_{i} \mathbf{C}_{i}
$$


where $\mathbf{C}_{i}$ are the covariance matrices of $\mathbf{M}_{i}$ and given by

$$
\mathbf{C}_{i}=\mathbf{e}_{i} \mathbf{e}_{i}^{\dagger}
$$

where $\mathbf{e}_{i}$ are eigenvectors of $\mathbf{C}$ and $\dagger$ is the symbol for Hermitian conjugate. To obtain $\mathbf{M}_{i}$ we calculate

$$
\mathbf{M}_{i j}=\frac{1}{4} \operatorname{tr}\left(C_{i j}\left(\sigma_{i} \otimes \sigma_{j}^{*}\right)\right)
$$

where $\operatorname{tr}$ stands for the trace operation. We now have the $\lambda_{i}$ 's from equation 4.1 as the eigenvalues of $\mathbf{C}$ obtained from equation 4.4. In papers VI and VII Mueller matrices of beetles of the species Cetonia aurata and Chrysina argenteola have been used as examples for decomposition. These Mueller matrices are clearly depolarizing since they have very high values of $Q_{\text {JM }}$ as seen in figures 4.1 and 4.2.

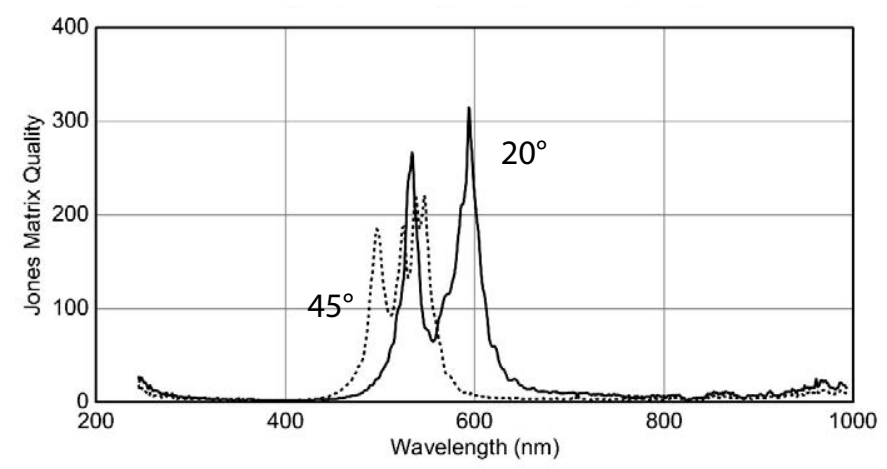

Figure 4.1. The Jones Matrix Quality at two incidence angles $\left(20^{\circ}\right.$ and $\left.45^{\circ}\right)$ of the experimental data of C. aurata.

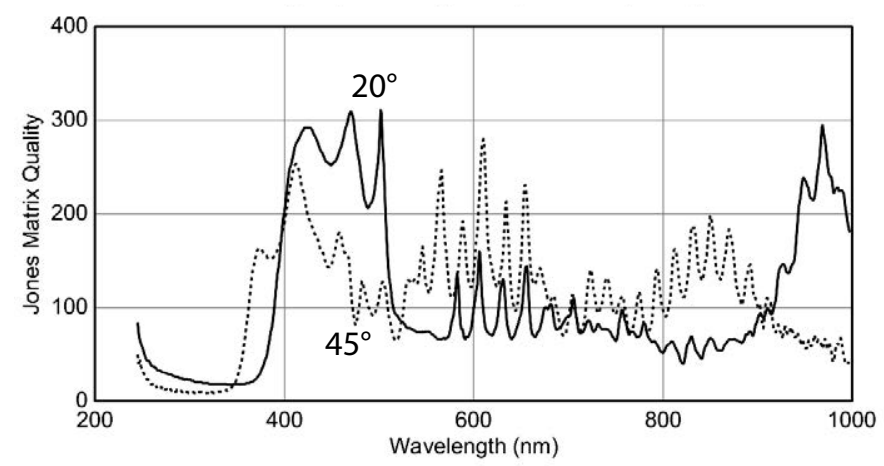

Figure 4.2. The Jones Matrix Quality at two incidence angles $\left(20^{\circ}\right.$ and $\left.45^{\circ}\right)$ of the experimental data of $C$. argenteola. 
For an experimentally determined Mueller matrix of a beetle of the species C. aurata, a Cloude decomposition results in one graph showing $\lambda_{i}$ as a function of wavelength (figure 4.3) and four graphs showing the matrices $\mathbf{M}_{i}$ as functions

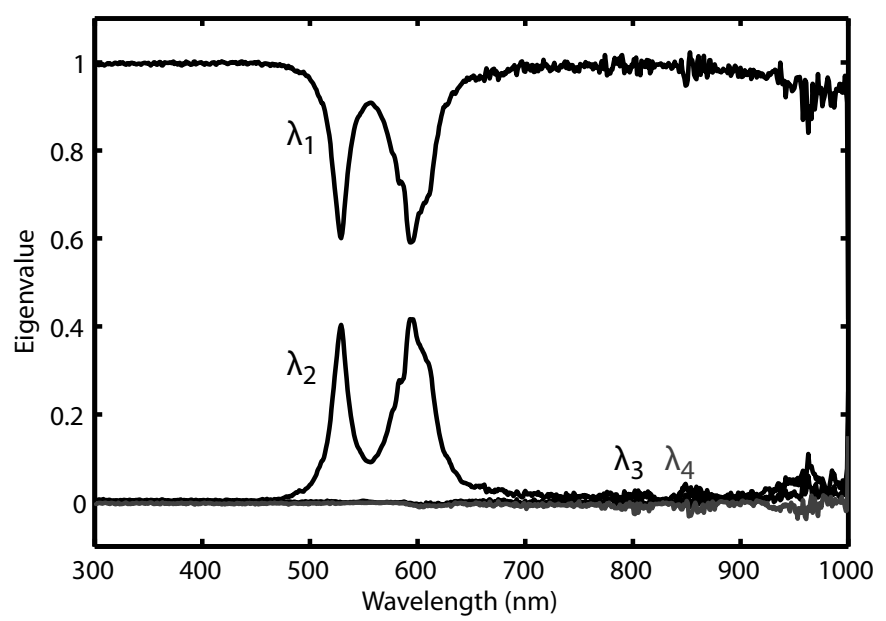

Figure 4.3. The eigenvalues $\lambda_{i}$ after Cloude decomposition. $\lambda_{1}$ is clearly distinguishable in the entire spectrum as well as $\lambda_{2}$ between $500 \mathrm{~nm}$ and $700 \mathrm{~nm}$. Outside that range $\lambda_{2}, \lambda_{3}$ and $\lambda_{4}$ all have values close to zero.

of wavelength (figure 4.4). This decomposition is done in paper VI but here also the four $\mathbf{M}_{i}$ are presented as obtained. The eigenvalue analysis is made on $\mathbf{C}$ in Matlab, as described in paper VI, and the resulting eigenvalues are ordered according to numerical value and not according to which eigenvector they are associated with. This problem propagates to the determination of $\mathbf{M}_{i}$ which are calculated according to equations 4.5 and 4.6. Therefore when there is an interchange in the eigenvalue, there is a corresponding interchange in the eigenvector and therefore also in $\mathbf{M}_{i}$ which is clearly seen in figures 4.3 and 4.4 at $529 \mathrm{~nm}$ and $593 \mathrm{~nm}$. In paper VI this has been addressed and the eigenvalues have been sorted manually. In practice this is done by replacing $m_{i j}$-data for $\mathbf{M}_{1}$ with data from $\mathbf{M}_{2}$ and vice versa in the spectral range $529-593 \mathrm{~nm}$.

In section 4.2 an alternative to Cloude decomposition is presented where this problem is dealt with in a different way. Since two of the eigenvalues, $\lambda_{3}$ and $\lambda_{4}$, are close to zero in the entire spectral range they are disregarded and equation 4.1 becomes

$$
\mathbf{M}=\lambda_{1} \mathbf{M}_{1}+\lambda_{2} \mathbf{M}_{2}
$$

We can now look at the matrices $\mathbf{M}_{1}$ and $\mathbf{M}_{2}$ in figure 4.4 and, taking the interchange of eigenvalues into account, identify a dielectric mirror and a left-handed circular polarizer, respectively. It is now clear that the Mueller matrix measured can be decomposed into a sum of a dielectric mirror and a left-handed circular polarizer weighted by the eigenvalues $\lambda_{1}$ and $\lambda_{2}$, respectively.

The effect of a Cloude decomposition is that a depolarizing Mueller matrix can 
be represented as a sum of non-depolarizing Mueller matrices. The eigenvalues, $\lambda_{i}$, are all non-negative for a physically realizable Mueller matrix. However, if a negative eigenvalue is obtained it means that the Mueller matrix is non-physical. An experimentally determined Mueller matrix can be non-physical due to i.e. instrumental imperfections. By filtering out the negative eigenvalue and only keeping the non-negative in equation 4.1 it is possible to obtain a closest physical representation of a non-physical experimental Mueller matrix.

One other effect of the decomposition is that when depolarization is caused by an inhomogeneous sample with regions of different optical properties the Mueller matrices of the different regions can be retrieved under certain conditions [22]. In the example above it is uncertain whether the depolarization is caused by an inhomogeneous surface or if the depolarization is an intrinsic feature in the structured cuticle of the beetle, as is discussed in paper VI.

As stated above, the result of a Cloude decomposition is a set of physically realizable non-depolarizing Mueller matrices. The fact that the matrices which are the result of a Cloude decomposition of $C$. aurata are representations of a pure mirror and a pure circular polarizer is due to the sample under inspection. With a different sample other matrices, which do not represent pure optical devices, could very well be the result of decomposition. This is the case with a beetle of the species Chrysina argenteola which is discussed in paper VI. C. argenteola decomposes into a set of three matrices representing a mirror, a circular polarizer and a third, so far unidentified matrix.

\subsection{Regression decomposition}

An alternative to a Cloude decomposition is a regression decomposition. Here we relax the constraint that the the result of the decomposition should be nondepolarizing Mueller matrices, and allow them to be any $4 \times 4$ matrices. In theory, we also allow an infinite number of matrices. In practice we only allow four terms in the sum to keep the comparability to Cloude decomposition, so that the regression equivalent of the Cloude equation 4.1 becomes

$$
\mathbf{M}^{r e g}=a \mathbf{M}_{1}^{r e g}+b \mathbf{M}_{2}^{r e g}+c \mathbf{M}_{3}^{r e g}+d \mathbf{M}_{4}^{r e g}
$$

That is, any Mueller matrix $\mathbf{M}$ can be decomposed into a set of up to four matrices $\mathbf{M}_{i}$ which are specified beforehand. We can therefore limit the constraint further to only use Mueller matrices representing pure optical devices. This leaves $a, b, c$ and $d$ as fit parameters to minimize the Frobenius norm

$$
\left\|\mathbf{M}^{e x p}-\mathbf{M}^{r e g}\right\|_{F}
$$

where $\mathbf{M}^{\exp }$ is the experimentally determined Mueller matrix to be decomposed. Depending on $\mathbf{M}^{e x p}$ an appropriate choice of $\mathbf{M}_{i}^{r e g}$ matrices has to be made and different values of $a, b, c$ and $d$ are obtained through regression analysis. A Cloude decomposition can be a valuable tool in deciding which set of $\mathbf{M}_{i}^{\text {reg }}$ should be used. In paper VI regression decomposition of data from C. aurata was applied 
with

$$
\mathbf{M}_{1}^{r e g}=\left[\begin{array}{cccc}
1 & 0 & 0 & 0 \\
0 & 1 & 0 & 0 \\
0 & 0 & -1 & 0 \\
0 & 0 & 0 & -1
\end{array}\right] \quad \mathbf{M}_{2}^{r e g}=\left[\begin{array}{cccc}
1 & 0 & 0 & -1 \\
0 & 0 & 0 & 0 \\
0 & 0 & 0 & 0 \\
-1 & 0 & 0 & 1
\end{array}\right]
$$

i.e. a mirror and a circular polarizer as in the Cloude decomposition. The resulting $a$ and $b$ showed excellent agreement with the eigenvalues, $\lambda_{1}$ and $\lambda_{2}$, obtained with Cloude decomposition.

Instead of specifying the exact matrices to be used in the ansatz, general versions of pure optical devices can be used. In paper VII we used regression decomposition with an elliptical polarizer and a general retarder and set the ellipticity of the polarizer and the retardance of the retarder to be fittable parameters as well as the coefficients $\alpha$ and $\beta$. We also extended the decomposition to include multiple incidence angles. The ansatz was

$$
\mathbf{M}^{\text {reg }}=a(\lambda, \theta) \mathbf{M}_{P}^{\text {elliptic }}(\varepsilon)+b(\lambda, \theta) \mathbf{M}_{R}^{\text {linear }}(\alpha, \delta)
$$

where $\lambda$ and $\theta$ are the wavelength and incidence angle, respectively, $\mathbf{M}_{P}^{\text {elliptic }}$ is the Mueller matrix of an elliptical polarizer as described in equation 3.29 and $\mathbf{M}_{R}^{\text {linear }}$ is the Mueller matrix of a linear retarder as in equation 3.31 where $\delta$ is the phase delay and $\alpha$ is the orientation angle. The result of such a decomposition in terms of $a, b, \varepsilon, \alpha$ and $\delta$ is found in paper VII. It is found there that the Mueller matrix of $C$. aurata can be decomposed into (I) an elliptical polarizer which represents a circular polarizer or a horizontal polarizer depending on incidence angle and wavelength and (II) a retarder which represents a mirror or a linear retarder depending on incidence angle and wavelength. In figure 4.5 the experimentally determined Mueller matrix of the beetle $C$. aurata can be seen. Measurements were performed in steps of $1^{\circ}$ in $\lambda$ and $\theta$, respectively. The aim of the decomposition is to have a value of $\mathbf{M}^{r e g}$ to be as close to the experimentally determined $\mathbf{M}$ as possible. To visualize the fit the matrix $\mathbf{M}^{r e g}$ is shown in figure 4.6, and the difference $\mathbf{M}^{r e g}-\mathbf{M}$ can be seen in figure 4.7 .

It is clear from figure 4.7 that $\mathbf{M}^{r e g}-\mathbf{M}$ is not zero in all points, as would mean a perfect fit. There are differences especially where the Mueller matrix $\mathbf{M}$ shifts from representing a left-handed circular polarizer to representing a horizontal linear polarizer in elements $m_{14}$ and $m_{41}$ but also throughout the elements $m_{11}$, $m_{12}, m_{21}, m_{22}, m_{33}$ and $m_{44}$ where the experimental value is lower than the value of $\mathbf{M}^{r e g}$. The process of selecting the matrices in the ansatz has been one of trial and error and only matrices representing pure devices has been used. 

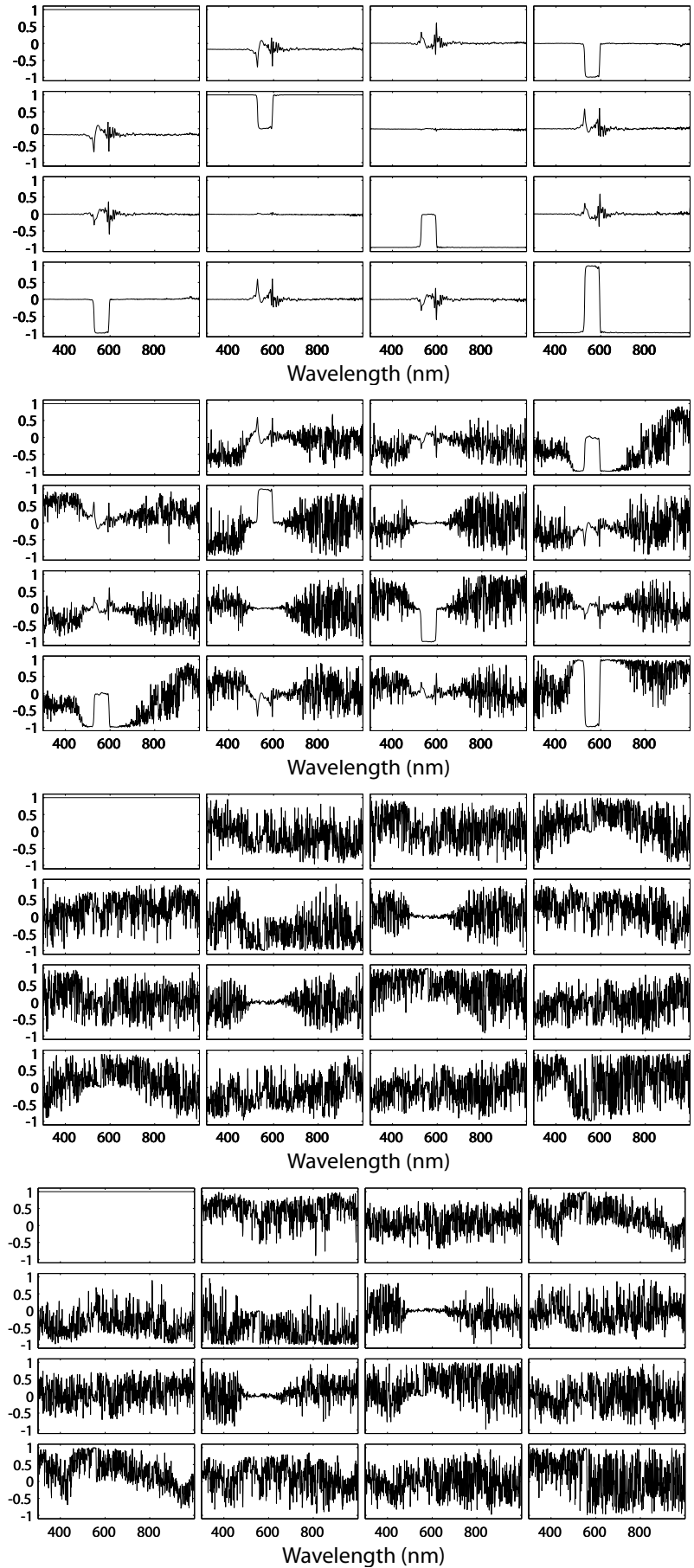

Figure 4.4. The (normalized) Mueller matrices $\mathbf{M}_{i}$ after Cloude decomposition. From top to bottom: $\mathbf{M}_{1}, \mathbf{M}_{2}, \mathbf{M}_{3}, \mathbf{M}_{4}$. 


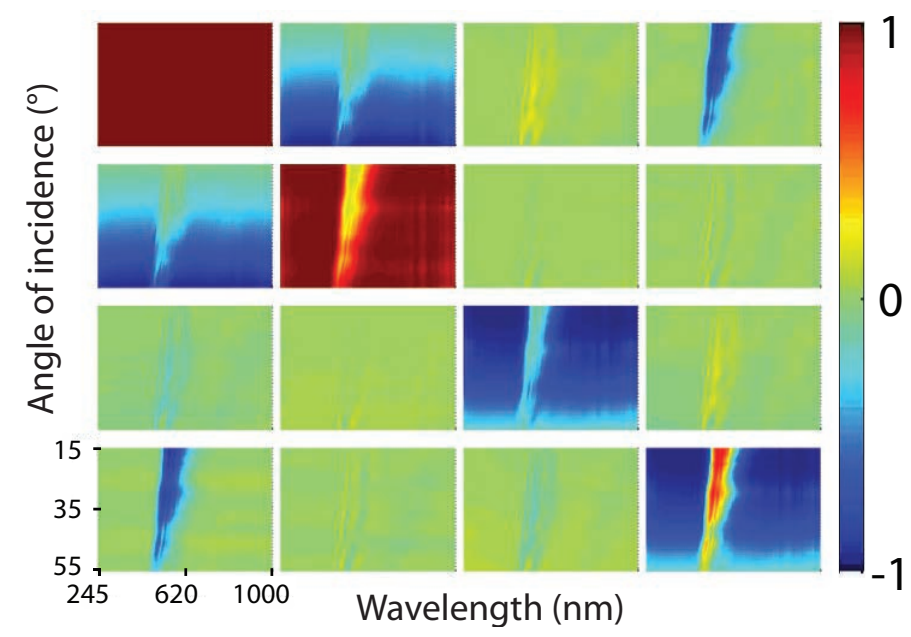

Figure 4.5. Experimentally determined Mueller matrix $\mathbf{M}$ of the scarab beetle Cetonia aurata.

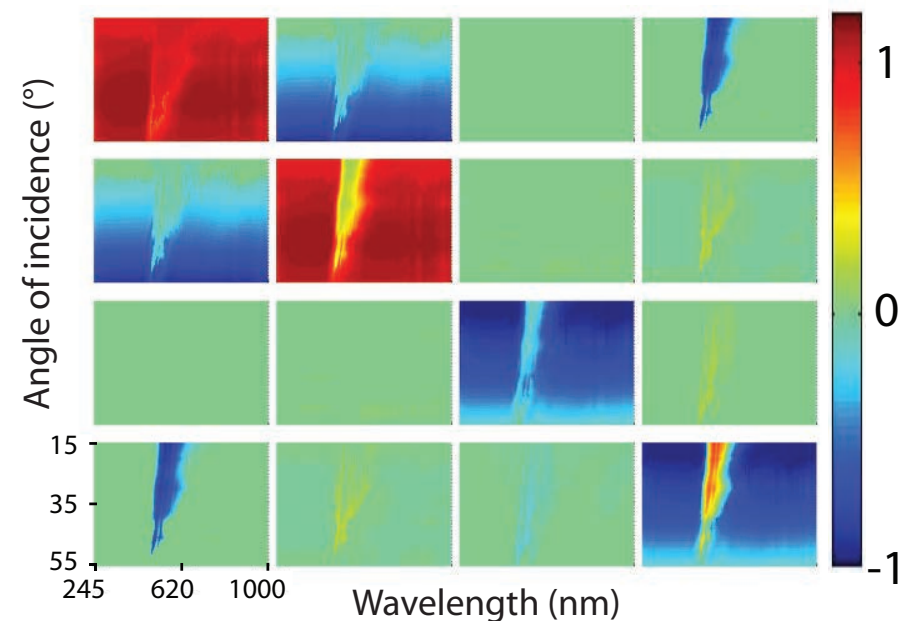

Figure 4.6. $\mathbf{M}^{\text {reg }}$ when a Mueller matrix of the scarab beetle Cetonia aurata is decomposed according to the ansatz in equation 4.11. 


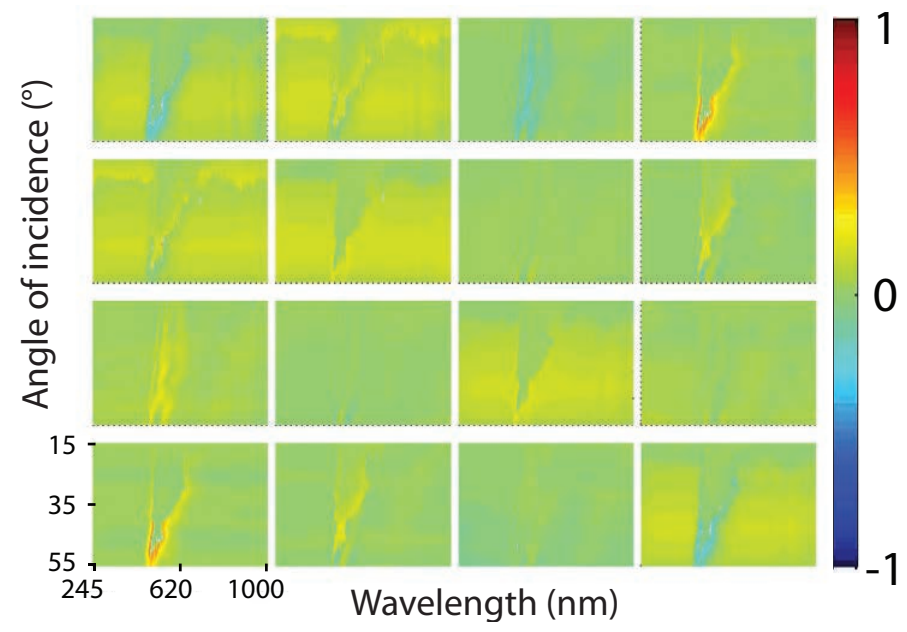

Figure 4.7. $\mathbf{M}^{\text {reg }}-\mathbf{M}$ when a Mueller matrix of the scarab beetle Cetonia aurata is decomposed according to the ansatz in equation 4.11. 


\section{Chapter 5}

\section{Photonic crystals}

A photonic crystal is a material with a periodicity in the dielectric function comparable to the wavelength of light. Because of the periodicity light waves have limited possibilities to propagate inside the material.

The optical properties of photonic crystals are governed mainly by diffraction. When a wave hits an object with size comparable to the wavelength it may change its direction of propagation, it diffracts. This can be visualized by Huygen's principle [16], which states that every point reached by a wavefront becomes a point source of the wave itself. When adding up many such waves originating from point sources, a new wavefront is obtained. If these point sources are distributed periodically in space, destructive and constructive interference can give the result that only certain directions are allowed for the light to propagate in.

\subsection{Bragg diffraction}

If reflecting objects (or scatterers) are distributed in space with a distance $d$ from each other, and light of wavelength $\lambda$ shines on them at an angle $\beta$ as defined in figure 5.1, constructive interference will occur when

$$
n \lambda=2 d \sin \beta
$$

where $n=1,2,3, \ldots$ If $n=\frac{1}{2}, \frac{3}{2}, \frac{5}{2}, \ldots$ equation 5.1 will instead result in destructive interference.

\subsection{Circular Bragg phenomenon}

In paper II nanospirals with a fourfold staircase morphology are studied. Due to their chiral nature they reflect light with a high degree of circular polarization. Left-handed spirals reflect left-handed near-circular polarization and right-handed 


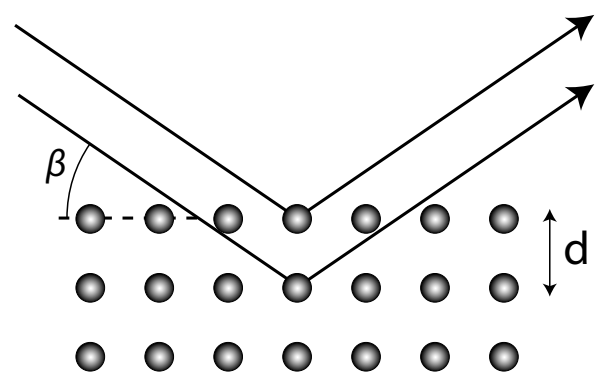

Figure 5.1. Light interaction with a periodic array of scatterers.

spirals reflect right-handed near-circular polarization. In paper III similar structures are shown but in this case the structure is not a staircase structure but continuously chiral.

In a chiral structure like the ones described, light of the same handedness as the structure is strongly reflected within a certain wavelength regime called the Bragg zone [23]. An approximate center wavelength $\lambda^{B r}$ of the Bragg regime can be calculated according to

$$
\lambda^{B r} \simeq \Omega\left(n_{x}+n_{y}\right) \sqrt{\cos \theta}
$$

where $\Omega$ is half the structural period of the chiral structure, $n_{x}$ and $n_{y}$ are the refractive indices in two orthogonal directions of the material and $\theta$ is the incidence angle. In paper III an optical model was made and structural as well as optical parameters were extracted for the films of nanospirals. These parameters were used to calculate where the center of the Bragg regime should be for the samples studied. The result is displayed in table 5.1 and compared to the peak value $\lambda_{E x p}^{B r}$ in $m_{41}$ in the experimental data.

\begin{tabular}{llllll}
\hline Chiral structure & $\Omega(\mathrm{nm})$ & $n_{x}$ & $n_{y}$ & $\lambda^{B r}(\mathrm{~nm})$ & $\lambda_{\text {Exp }}^{B r}(\mathrm{~nm})$ \\
\hline & & & & & \\
Left handed & 124 & 1.68 & 1.72 & 401 & 423 \\
Right handed & 106 & 1.72 & 1.75 & 350 & 370
\end{tabular}

Table 5.1. Calculated position of Bragg regime using parameters from paper III

There is a discrepancy between the experimentally determined Bragg peak position and $\lambda^{B r}$ calculated from equation 5.2 of $6 \%$ for both the right-handed and the left-handed nanostructures which is a good match considering the circumstances. Equation 5.2 is based on perfect conditions whereas the experimental 
data is not taken of a perfect helicoidal structure, but a real, physical structure not completely devoid of imperfections. In addition, the Mueller matrix spectra has an overlaying thin film interference pattern which may influence the peak position. The top transparent layer present in the model might also interfere. Furthermore, equation 5.2 requires a semi-infinite film which is obviously not the case. 


\section{Chapter 6}

\section{Ellipsometry}

Ellipsometry is a technique very well suited for optical and structural characterization of surfaces and thin films. Paul Drude described the principles of ellipsometry in the late 19th century and conducted the first experiments [24]. Since then much has changed, especially with the invention of computers.

In this work only reflection-based ellipsometry has been used. In reflection mode light of a known polarization state is shone on a sample surface which may include one or more thin films, and the polarization state of the reflected light is analyzed.

\subsection{Standard ellipsometry}

In papers IV and V standard ellipsometry was used to characterize structural properties of square lattices of carbon nanofibers. The basic quantity measured in standard ellipsometry is

$$
\rho=\frac{\chi_{r}}{\chi_{i}}
$$

where $\chi_{i}$ and $\chi_{r}$ are complex-number representations of the state of polarization of the incident and reflected light, respectively. Using the coordinate system from figure 6.1, with $p$-polarized light parallel and $s$-polarized light perpendicular to the plane of incidence, $\chi$ can be expressed as

$$
\chi_{r}=\frac{E_{r p}}{E_{r s}} \quad \text { and } \quad \chi_{i}=\frac{E_{i p}}{E_{i s}}
$$

Combining equations 6.1 and 6.2 gives

$$
\rho=\frac{E_{r p}}{E_{r s}} \frac{E_{i s}}{E_{i p}}=\frac{r_{p}}{r_{s}}=\tan \Psi e^{i \Delta}
$$

where $r_{p}$ and $r_{s}$ are the complex-valued reflection coefficients for the sample for $p$ - and $s$-polarization, respectively, and $\Psi$ and $\Delta$ are the so called ellipsometric 

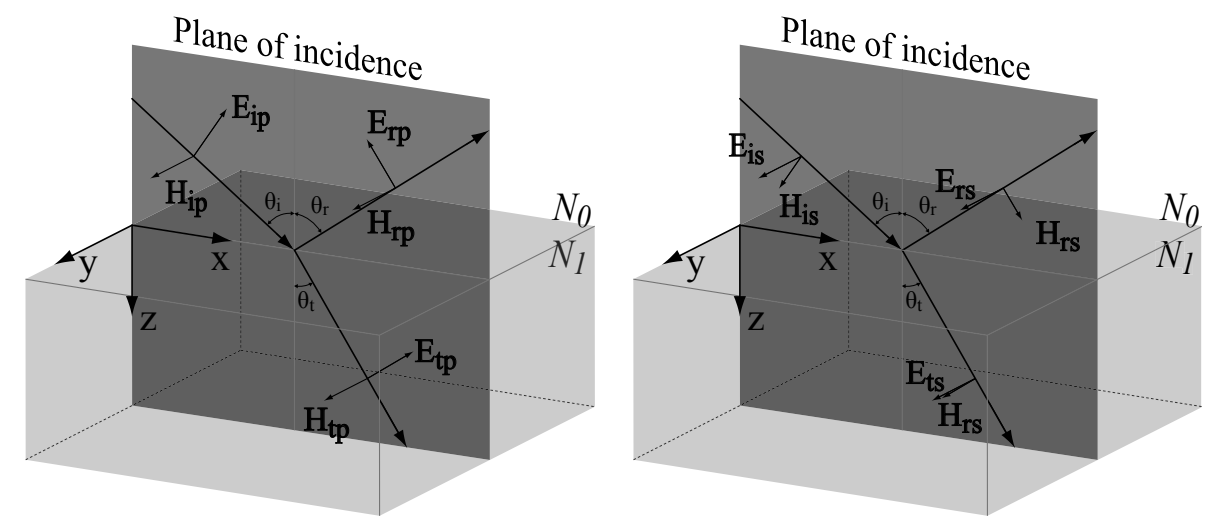

Figure 6.1. The $p$ - (left) and $s$ - (right) components of the electric field for polarized light reflected and transmitted at a surface. The corresponding magnetic field components $\mathbf{H}_{i}, \mathbf{H}_{r}$ and $\mathbf{H}_{t}$ are also shown. $\theta_{i}, \theta_{r}$ and $\theta_{t}$ are the angles of incidence, reflection and refraction, respectively. $N_{0}$ and $N_{1}$ are the refractive indices of the ambient and the substrate, respectively.

angles [25]. Here we have assumed that there is no coupling between the orthogonal $p$ - and $s$-polarizations, i.e. the Jones matrix ${ }^{1}$ of the sample is diagonal. This is the case for isotropic samples, for uniaxial samples when the optical axis is parallel to the sample normal and for some additional symmetric orientations of anisotropic samples. If the sample is otherwise anisotropic, coupling between pand s-polarizations occurs and generalized ellipsometry [25] has to be used to extract the off-diagonal elements of the Jones matrix. Since Jones calculus only handles completely polarized light, standard or generalized ellipsometry should not be used when the reflected light is partially polarized, e.g. when studying reflection from depolarizing samples.

\subsection{Mueller-matrix ellipsometry}

In papers I, II, III, VI and VII Mueller-matrix ellipsometry has been used to measure the polarizing properties of different samples. When a sample exhibit depolarization standard ellipsometry is not sufficient to describe the polarization properties and a Mueller matrix should be used. A Mueller matrix also provides redundancy leading to increased accuracy for complicated samples. As described in section 3.2, a Stokes vector is used to describe the polarization state of the light and a Mueller matrix describes the transformation from the incident polarization state to the emerging state. If a sample can be described by a Jones matrix the relationship between the Jones matrix and the Mueller matrix can be calculated from equation 3.41 .

\footnotetext{
${ }^{1}$ In Jones calculus polarized light is described by a $2 \times 1$ complex column vector, the Jones vector, and an optical element is described by a $2 \times 2$ complex matrix, the Jones matrix [26].
} 
In a Mueller-matrix ellipsometry experiment, light with sufficient variation in a Stokes vector, $\mathbf{S}_{i}$ is incident on a sample and the corresponding reflected Stokes vector $\mathbf{S}_{o}$ is analyzed. From the relation $\mathbf{S}_{o}=\mathbf{M} \mathbf{S}_{i}$ (see equation 3.21) the 16 elements of the sample Mueller matrix are determined. For a non-depolarizing and anisotropic sample with non-diagonal Jones matrix

$$
\mathbf{J}=\left[\begin{array}{ll}
r_{p p} & r_{s p} \\
r_{p s} & r_{s s}
\end{array}\right]
$$

the Mueller matrix elements are given by

$$
\begin{aligned}
& m_{11}=\frac{1}{2}\left(\left|r_{p p}\right|^{2}+\left|r_{s s}\right|^{2}+\left|r_{s p}\right|^{2}+\left|r_{p s}\right|^{2}\right) \\
& m_{12}=\frac{1}{2}\left(\left|r_{p p}\right|^{2}-\left|r_{s s}\right|^{2}-\left|r_{s p}\right|^{2}-\left|r_{p s}\right|^{2}\right) \\
& m_{13}=\Re\left[r_{p p} r_{s p}^{*}+r_{s s} r_{p s}^{*}\right] \\
& m_{14}=\Im\left[r_{p p} r_{s p}^{*}+r_{s s} r_{p s}^{*}\right] \\
& m_{21}=\frac{1}{2}\left(\left|r_{p p}\right|^{2}-\left|r_{s s}\right|^{2}+\left|r_{s p}\right|^{2}-\left|r_{p s}\right|^{2}\right) \\
& m_{22}=\frac{1}{2}\left(\left|r_{p p}\right|^{2}+\left|r_{s s}\right|^{2}-\left|r_{s p}\right|^{2}-\left|r_{p s}\right|^{2}\right) \\
& m_{23}=\Re\left[r_{p p} r_{s p}^{*}-r_{s s}^{*} r_{p s}\right] \\
& m_{24}=\Im\left[r_{p p} r_{s p}^{*}-r_{s s}^{*} r_{p s}\right] \\
& m_{31}=\Re\left[r_{p p} r_{p s}^{*}+r_{s s}^{*} r_{s p}\right] \\
& m_{32}=\Re\left[r_{p p} r_{p s}^{*}-r_{s s}^{*} r_{s p}\right] \\
& m_{33}=\Re\left[r_{p p} r_{s s}^{*}+r_{p s}^{*} r_{s p}\right] \\
& m_{34}=\Im\left[r_{p p} r_{s s}^{*}-r_{p s}^{*} r_{s p}\right] \\
& m_{41}=-\Im\left[r_{p p} r_{p s}^{*}+r_{s s}^{*} r_{s p}\right] \\
& m_{42}=-\Im\left[r_{p p} r_{p s}^{*}-r_{s s}^{*} r_{s p}\right] \\
& m_{43}=-\Im\left[r_{p p} r_{s s}^{*}+r_{p s}^{*} r_{s p}\right] \\
& m_{44}=\Re\left[r_{p p} r_{s s}^{*}-r_{p s}^{*} r_{s p}\right]
\end{aligned}
$$

where $\Re$ and $\Im$ denote real part and imaginary part, respectively. For an isotropic sample $\left(r_{p s}=r_{s p}=0\right)$ this simplifies to

$$
\mathbf{M}=\left[\begin{array}{cccc}
\frac{1}{2}\left(\left|r_{p}\right|^{2}+\left|r_{s}\right|^{2}\right) & \frac{1}{2}\left(\left|r_{p}\right|^{2}-\left|r_{s}\right|^{2}\right) & 0 & 0 \\
\frac{1}{2}\left(\left|r_{p}\right|^{2}-\left|r_{s}\right|^{2}\right) & \frac{1}{2}\left(\left|r_{p}\right|^{2}+\left|r_{s}\right|^{2}\right) & 0 & 0 \\
0 & 0 & \Re\left[r_{p} r_{s}^{*}\right] & -\Im\left[r_{p} r_{s}^{*}\right] \\
0 & 0 & \Im\left[r_{p} r_{s}^{*}\right] & \Re\left[r_{p} r_{s}^{*}\right]
\end{array}\right]
$$

Due to the complexity of $\mathbf{M}$, it is normally not processed further. A few exceptions are derivation of emerging state of polarization for a given $\mathbf{S}_{i}$ as presented in paper I and Cloude decompositions as described in papers VI and VII. However, in a majority of applications $\mathbf{M}$ is used directly as input data in modeling of sample properties as briefly discussed in section 6.4 


\subsection{Ellipsometer setup}

In all parts of this work a dual-rotating-compensator ellipsometer named $\mathrm{RC} 2{ }^{\circledR}$ from J.A. Woollam Co., Inc has been used to determine the Mueller matrices of various samples.

The principle of a dual rotating compensator ellipsometer can be seen in figure 6.2. Unpolarized light from the light source propagates through a polarizer

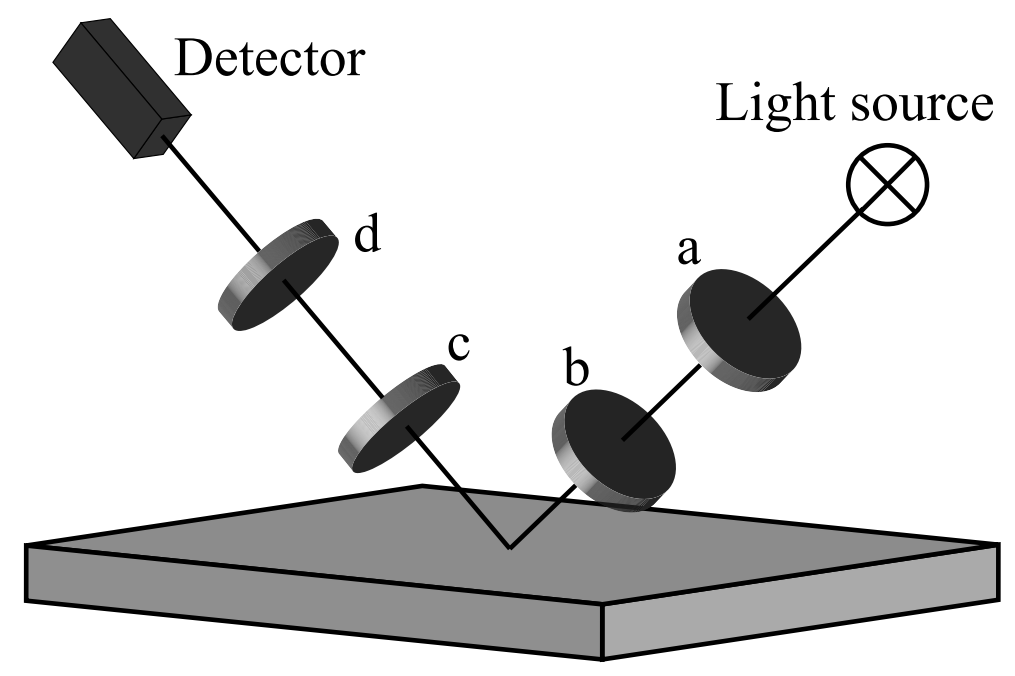

Figure 6.2. A schematic description of a dual rotator compensator ellipsometer. Components a and $\mathrm{d}$ are polarizers and components $\mathrm{b}$ and $\mathrm{c}$ are compensators.

and then through the first rotating compensator. After reflection off the sample the light propagates through a second rotating compensator and finally an analyzer before it arrives at the detector. This setup allows for multiple different polarization states of the incident light, including linear, circular and elliptical, as well as detection of all different polarization states. This configuration was proposed by Azzam [27] and the angular speeds of the rotating compensators are $\omega$ and $5 \omega$. Azzam described an instrument with perfect quarter-wave retarders and Hague [28] expanded the design to include the use of imperfect compensators to allow for spectral variations. Later Collins and Koh [29] showed that a frequency ratio of the compensators of 5:3 would allow for higher rotational speed and stability of the compensators. If the fundamental mechanical frequency of the system is $\omega_{B}$, a configuration as the one in figure 6.2 , with the frequency of the first compensator being $\omega_{c 1}=5 \omega_{B}$ and of the second compensator $\omega_{c 2}=3 \omega_{B}$, will yield a signal $I(t)$ at the detector as

$$
I(t)=I_{0}\left[1+\sum_{n=1}^{16}\left(\alpha_{2 n} \cos \left(2 n C-\phi_{2 n}\right)+\beta_{2 n} \sin \left(2 n C-\phi_{2 n}\right)\right)\right]
$$

where $\alpha_{2 n}$ and $\beta_{2 n}$ are the normalized Fourier coefficients and $C=\omega_{B} t$. The phase 
angles $\phi_{2 n}$ are defined in reference [29]. The Fourier analysis of the modulated signal provides 24 non-zero ac coefficients (and 8 zero-valued) from which the 15 normalized Mueller matrix elements can be calculated (see Collins and Koh [29] for details). Alternatively, $\Psi$ and $\Delta$ can be calculated from the Fourier coefficients in case measurements are done on isotropic and non-depolarizing samples.

\subsection{Analysis}

Ellipsometry is an indirect technique for analyzing materials in the sense that $\Psi$ and $\Delta$ or the Mueller matrix in most cases do not reveal direct information on refractive indices of the sample constituent(s), layer thickness(es) or structural properties ${ }^{2}$. Normally a model analysis has to be performed to retrieve any substantial information. In paper III such modeling was performed to find the refractive indices of biaxial materials as well as structural properties such as layer thicknesses and orientations of optical axes. Standard multilayer Fresnel-based formalism with biaxial refractive indices were used $[15,30]$

Data are generated from the model and compared to the experimental data. The parameters in the model are then tweaked to minimize the difference between the generated and experimental data. This is done in an iterative process and the Levenberg-Marquardt algorithm is used to minimize the mean squared error

$$
M S E=\frac{1000}{L-M} \sum_{l=1}^{L} \sum_{i, j=1}^{4}\left[\left(m_{i j, l}^{e x p}-m_{i j, l}^{\bmod }(\mathbf{x})\right)^{2}\right]
$$

where $L$ is the number of Mueller matrices, i.e. number of wavelengths, $M$ is the number of fit parameters in the parameter vector $\mathbf{x}$ and $m_{i j, l}^{e x p}$ and $m_{i j, l}^{\text {mod }}$ are experimental and model calculated Mueller-matrix elements, respectively.

To model the materials properties $N=n+i k$ in paper III the Cauchy dispersion model was used for $n$ and to model $k$ an Urbach tail was added

$$
\begin{gathered}
n=A+\frac{B}{\lambda^{2}}+\frac{C}{\lambda^{4}} \\
k=D e^{E\left(\frac{1}{\lambda}-\frac{1}{F}\right)}
\end{gathered}
$$

Here $A, B, C, D$ and $E$ are constants determined in the fitting process and $\lambda$ is the wavelength. The parameter $F$ is directly correlated to $D$ and is not fitted. This model is commonly used for determining optical constants of transparent or weakly absorbing films. Several other models can be used to extract information from ellipsometry data and are discussed by Fujiwara [15].

\footnotetext{
${ }^{2}$ The so called pseudo refractive index of bulk samples with thin overlayers or small roughness can be directly determined, but it does not apply in this work.
} 


\section{Chapter 7}

\section{Sample preparation}

\subsection{Carbon nano fibers}

Carbon Nano Fibers (CNF) were produced by a plasma-enhanced chemical vapor deposition (PE-CVD) process. Electron-beam lithography was used to place nickel catalyst particles in desired patterns on a Ti substrate covered with a $20 \mathrm{~nm}$ titanium nitride layer. The CNF:s were grown via a tip-growth mechanism meaning that each individual CNF grows under the Ni-particle. After growth the Niparticles are still situated on the top of the CNF:s as described in figure 1 of paper IV. Rectangular as well as quadratic patterns were made with random patterned samples as reference. The CNF:s were approximately $1 \mu \mathrm{m}$ long and $50 \mathrm{~nm}$ in diameter. The fill factor was $0.8 \%$ for the samples with CNF:s in square lattices.

In the case with tunable CNF:s, electrodes of TiN were deposited by reactive sputtering and patterned using electron-beam lithography. The CNF:s where then grown as described above on top of the electrodes. In figure 1 in paper $\mathrm{V}$ a scanning electron microscopy image of such a sample can be seen where electrodes and CNF:s are clearly displayed.

Further sample preparation details can be found in a paper by R. Rehammar, R. Magnusson et al. [31] and more detailed descriptions have been made by Kabir et al. [32] and by R. Rehammar in his PhD thesis [33].

\section{$7.2 \operatorname{In}_{x} \mathrm{Al}_{1-x} \mathrm{~N}$}

$\mathrm{In}_{x} \mathrm{Al}_{1-x} \mathrm{~N}$ nanograss has been reported [34] where columnar structures were produced by curved-lattice epitaxial growth (CLEG). Co-sputtering with dual targets of $\mathrm{Al}$ and In results in a higher $\mathrm{Al}$ content on one side and a higher In content on the other side of each individual nanocolumn. The co-sputtering process is schematically shown in figure 7.1. The gradation of material content having different lattice parameters results in a curved single-crystalline structure. Another 


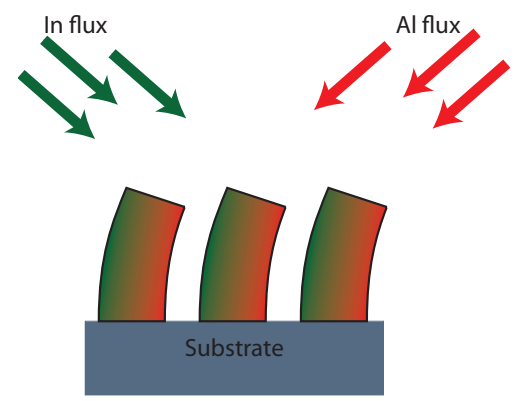

Figure 7.1. A schematic of the CLEG process. The material flux incident from different directions will yield a higher In-content in the parts colored green and a higher Al-content in the parts colored red.

result of the gradation is a difference in refractive index parallel to and perpendicular to the gradient. Here we have used the CLEG technique and extended the process by rotating the substrate during growth. This will produce a chiral structure where the internal gradient of the refractive index rotates within each nanocolumn. Further details on the protocol for the substrate rotation procedure is given in papers IV and V.

\subsection{Scarab beetles}

The beetles studied in papers VI and VII are two different species from the Scarabaeidae family. The one that is most extensively studied here is Cetonia aurata (Linnaeus, 1758) which can be seen in figure 7.2(a). The specimens which were studied were collected in Sweden.

The second species is Chrysina argenteola (Bates, 1888). Only one specimen has been studied here which originates from Colombia and was on loan from $\mathrm{Mu}-$ seum of Natural History in Stockholm. A photo is shown in figure 7.2(b). The Mueller-matrix ellipsometry measurements were performed on the scutellum in all cases. The scutellum is a triangular area on the dorsal side of the beetle between the cover wings.

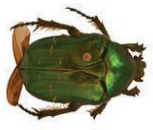

(a) Cetonia aurata

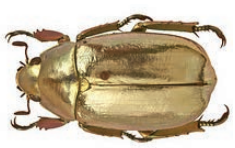

(b) Chrysina argenteola

Figure 7.2. The beetles used to record Mueller matrices for decomposition studies. 


\section{Chapter 8}

\section{Outlook}

\section{Carbon nanofibers}

I have shown that spectroscopic ellipsometry is a well suited technique to map out large regions of the optical band structure of carbon-nanofiber-based photonic crystals. In collaboration with colleagues at Chalmers University of Technology I have also shown that these photonic crystals can be made tunable by applying a charge on the individual nanofibers to change their shape due to electrostatic forces. In this case the shape is changed in a way that alters the periodicity of the photonic crystal. This change in the photonic crystal is detected with ellipsometry but signal from the photonic crystal is drowned out by the signal from the substrate to a large extent. However, as a proof-of-concept it shows that a 2D photonic crystal can be electrostatically actuated, opening up many possible applications and hopefully this work will stimulate further work in the field of optoelectronics.

\section{$\mathbf{I n}_{x} \mathbf{A l}_{1-x} \mathbf{N}$}

I have initiated optical studies of $\operatorname{In}_{x} \mathrm{Al}_{1-x} \mathrm{~N}$ nanospirals. So far I have studied only nanospirals with homogeneous pitch, i.e. the number of turns per length of the spirals does not change. A new system for physical vapor deposition with possibility to do glancing angle deposition has been installed at Linköping University recently. This will allow us to introduce new features and further customize the nanospirals. One obvious thing to explore is a change in pitch. This would change the wavelength region in which the sample reflects circularly polarized light. Initial trials to produce nanospirals with different pitch have been made, but so far without result. Fabrication of these structures is not trivial, but challenging and so far circularly polarizing samples have been made only in the ultraviolet regime. One goal is to make a sample that can reflect circularly polarized light in the visible regime. An extension of this goal is to make a broadband reflector by including multiple pitches in a sample. 
There are ongoing efforts to make films of nanospirals on transparent substrates with potential for transmission applications. Some pilot studies have been made and the results are awaiting interpretation.

\section{Decomposition}

Cloude decomposition is already an established technique used to filter experimentally determined Mueller matrices when unphysical contributions, e.g. from instrumental issues, are present.

The regression decomposition scheme described in this work is still in its infancy. It can be used as a tool to identify areas with different optical properties on a patterned surface, for instance. The Mueller matrices used are determined beforehand which makes it more stable than a Cloude decomposition where the resulting matrices can be very noisy. However, if it is to be a practical tool we need to develop the equations used in the anstaz in order to limit the trial-and-error to a minimum. In a long-term perspective decomposition of Mueller matrices may provide a means of polarization classification of natural reflectors analogous to the RGB- or CMYK-color models. 


\section{Bibliography}

[1] Parker, A.R., Townley, H.E., 2007. Biomimetics of photonic nanostructures. Nat. Nanotechnol. 2, 347-353. doi:10.1038/nnano.2007.152

[2] Potyrailo, R.A., Ghiradella, H., Vertiatchikh, A., Dovidenko, K., Cournoyer, J.R., Olson, E., 2007. Morpho butterfly wing scales demonstrate highly selective vapour response. Nature Photon. 1, 123-128. doi:10.1038/nphoton.2007.2

[3] Vigneron, J.P., Pasteels, J.M., Windsor, D.M., Vértesy, Z., Rassart, M., Seldrum, T., Dumont, J., Deparis, O., Lousse, V., Biró, L.P., Ertz, D., Welch, V., 2007. Switchable reflector in the Panamanian tortoise beetle Charidotella egregia (Chrysomelidae: Cassidinae). Phys. Rev. E 76, 031907. doi:10.1103/PhysRevE.76.031907

[4] Cheng, D.K., 1989. Field and Wave Electromagnetics, 2nd edition. AddisonWesley, Reading, Mass.

[5] Jackson, J.D., 1998. Classical Electrodynamics, 3rd edition. Wiley, New York.

[6] Pedrotti, F.L., Pedrotti, L.M., Pedrotti, L.S., 2006. Introduction to Optics, 3rd edition. Addison-Wesley, Upper Saddle River, N.J.

[7] Stokes, G.G., 2009. On the composition and resolution of streams of polarized light from different sources, in: Mathematical and Physical Papers, Cambridge Library Collection - Mathematics. Cambridge University Press.

[8] Hecht, E., 1970. Note on an Operational Definition of the Stokes Parameters. Am. J. Phys. 38, 1156-1158. doi:10.1119/1.1976574

[9] Goldstein, D.H., 2010. Polarized Light, 3rd edition. CRC Press, Boca Raton, FL.

[10] Chipman, R. 2009. Mueller matrices. In: Handbook of Optics, Volume I: Geometrical and Physical Optics, Polarized Light, Components and Instruments(set), 3rd edition. Bass, M., DeCusatis, C., Enoch, J., Lakshminarayanan, V., Li, G., MacDonald, C., Mahajan, V., Stryland, E.V. eds. McGraw-Hill Professional, New York. 
[11] Soleillet, P., 1929. Theses... par Paul Soleillet,... Sur les parametrés caractérisant la polarisation partielle de la lumiére dans les phénoménes de fluorescence. Masson, Paris.

[12] Perrin, F., 1942. Polarization of light scattered by isotropic opalescent media. J. Chem. Phys. 10, 415-427. doi:10.1063 1.1723743

[13] Mueller, H., 1943. Memorandum on the polarization optics of the photoelastic shutter. Report No. 2 of the OSRD project OEMsr-576

[14] Parke, N.G., 1948. Matrix Optics (Thesis). Massachusetts Institute of Technology.

[15] Fujiwara, H., 2007. Spectroscopic Ellipsometry: Principles and Applications. John Wiley \& Sons.

[16] Hecht, E., 2001. Optics, 4th edition. Addison-Wesley, Reading, Mass.

[17] Chipman, R. 2009. Polarimetry. In: Handbook of Optics, Volume II: Design, Fabrication and Testing, Sources and Detectors, Radiometry and Photometry, 3rd edition. Bass, M., DeCusatis, C., Enoch, J., Lakshminarayanan, V., Li, G., MacDonald, C., Mahajan, V., Stryland, E.V. eds. McGraw-Hill Professional, New York.

[18] Gil, J.J., Bernabéu, E., 1986. Depolarization and polarization indices of an optical system. Opt. Acta. 33, 185-189. doi:10.1080/713821924

[19] Chipman, R.A., 2005. Depolarization index and the average degree of polarization. Appl. Opt. 44, 2490-2495. doi:10.1364/AO.44.002490

[20] Cloude, S.R., 1989. Conditions for the physical realisability of matrix operators in polarimetry. Proc. SPIE 1166, Polarization Considerations for Optical Systems II, pp. 177-185. ; doi: 10.1117/12.962889

[21] Cloude, S.R., 1986. Group theory and polarisation algebra. Optik 75, 26-36.

[22] Foldyna, M., Garcia-Caurel, E., Ossikovski, R., De Martino, A., Gil, J.J., 2009. Retrieval of a non-depolarizing component of experimentally determined depolarizing Mueller matrices. Opt. Express 17, 12794-12806. doi:10.1364/OE.17.012794

[23] Lakhtakia, A., Messier, R., 2004. Sculptured Thin Films: Nanoengineered Morphology and Optics, SPIE Press monograph. SPIE Press, Bellingham, WA.

[24] Vedam, K., 1998. Spectroscopic ellipsometry: a historical overview. Thin Solid Films 313-314, 1-9. doi:10.1016/S0040-6090(97)00762-1

[25] Azzam, R.M.A., Bashara, N.M., 1987. Ellipsometry and Polarized Light. Elsevier, Amsterdam. 
[26] Jones, R.C., 1941. A new calculus for the treatment of optical systems. J. Opt. Soc. Am. 31, 488-493. doi:10.1364/JOSA.31.000488

[27] Azzam, R.M.A., 1978. Photopolarimetric measurement of the Mueller matrix by Fourier analysis of a single detected signal. Opt. Lett. 2, 148-150. doi:10.1364/OL.2.000148

[28] Hauge, P.S., 1978. Mueller matrix ellipsometry with imperfect compensators. J. Opt. Soc. Am. 68, 1519-1528. doi:10.1364/JOSA.68.001519

[29] Collins, R.W., Koh, J., 1999. Dual rotating-compensator multichannel ellipsometer: instrument design for real-time Mueller matrix spectroscopy of surfaces and films. J. Opt. Soc. Am. A 16, 1997-2006. doi:10.1364/JOSAA.16.001997

[30] J.A. Woollam Company, 2011. CompleteEASE ${ }^{\circledR}$ Software Manual. J.A. Woollam Co., Inc. Lincoln, Nebr.

[31] Rehammar, R., Magnusson, R., Lassesson, A., Arwin, H., Kinaret, J., Campbell, E., 2011. Carbon nanofiber-based photonic crystals-fabrication, diffraction and ellipsometry investigations, in: MRS Online Proceedings Library. pp. $28-33$.

[32] Kabir, M.S., Morjan, R.E., Nerushev, O.A., Lundgren, P., Bengtsson, S., Enoksson, P., Campbell, E.E.B., 2006. Fabrication of individual vertically aligned carbon nanofibres on metal substrates from prefabricated catalyst dots. Nanotechnology 17, 790. doi:10.1088/0957-4484/17/3/029

[33] Rehammar, R., 2012. Tunable photo crystals based on carbon nanofibers (Thesis). Chalmers University of Technology, Göteborg.

[34] Radnóczi, G.Z., Seppänen, T., Pécz, B., Hultman, L., Birch, J., 2005. Growth of highly curved $\mathrm{Al}_{1-x} \mathrm{In}_{x} \mathrm{~N}$ nanocrystals. Phys. Status Solidi (a) 202, R76R78. doi:10.1002/pssa.200510024 
Publications 



\section{List of publications}

[I] Hans Arwin, Roger Magnusson, Jan Landin, and Kenneth Järrendahl Chirality-induced polarization effects in the cuticle of scarab beetles: 100 years after Michelson

Phil. Mag. 92 no. 12, pp. 1583-1599 (2012)

[II] Roger Magnusson, Ching-Lien Hsiao, Jens Birch, Hans Arwin, and Kenneth Järrendahl

Chiral nanostructures producing near circular polarization

Opt. Mater. Express 4 no. 7, pp. 1389-1403 (2014)

[III] Roger Magnusson, Jens Birch, Per Sandström, Ching-Lien Hsiao, Hans Arwin, and Kenneth Järrendahl Optical mueller matrix modeling of chiral $A l_{x} I_{1-x} N$ nanospirals Thin Solid Films. In Press

[IV] Robert Rehammar, Roger Magnusson, Antoniao I. Fernandez-Dominguez, Hans Arwin, Jari M. Kinaret, Stefan. A. Maier, and Eleanor E. B. Campbell

Optical properties of carbon nanofiber photonic crystals Nanotechnology 21 no. 46, art.no. 465203 (2010)

[V] Robert Rehammar, Farzan Alavian Ghavanini, Roger Magnusson, Jari M. Kinaret, Peter Enoksson, Hans Arwin, and Eleanor E. B. Campbell Electromechanically tunable carbon nanofiber photonic crystal Nano Lett. 13 no. 2, pp. 397-401 (2013)

[VI] Hans Arwin, Roger Magnusson, E. Garcia-Caurel, C. Fallet, Kenneth Järrendahl, A. De Martino, and Razvigor Ossikovski Sum decomposition of Mueller-matrix images and spectra of beetle cuticles. Submitted 
[VII] Roger Magnusson, Razvigor Ossikovski, and Hans Arwin Sum regression decomposition of spectral and angle-resolved Mueller-matrices from biological reflectors.

In manuscript

\section{My contributions to the papers}

In paper I I contributed to the preceding work including technical development and discussions leading up to the paper. I took some part in the writing process.

In paper II I planned and performed all experiments regarding ellipsometry and wrote the paper.

In paper III I planned and performed all experiments regarding ellipsometry and modeling. I wrote the paper.

In paper IV I was responsible for planning and performing the ellipsometry experiments and took part in the writing process.

In paper V I was responsible for planning and performing the ellipsometry experiments and I took part in the writing process.

In paper VI I did all calculations regarding decomposition and took part in the writing process.

In paper VII I did all calculations regarding decomposition and wrote the manuscript. 


\section{Publications}

The articles associated with this thesis have been removed for copyright reasons. For more details about these see:

http://urn.kb.se/resolve?urn=urn:nbn:se:liu:diva-111947 